Review

\title{
Mesoporous Transition Metal Oxides for Supercapacitors
}

\author{
Yan Wang ${ }^{1}$, Jin Guo ${ }^{2}$, Tingfeng Wang ${ }^{2}$, Junfeng Shao ${ }^{2}$, Dong Wang ${ }^{2}$ and Ying-Wei Yang 1,* \\ 1 College of Chemistry, International Joint Research Laboratory of Nano-Micro Architecture \\ Chemistry (NMAC), State Key Laboratory of Inorganic Synthesis and Preparative Chemistry, \\ Jilin University, 2699 Qianjin Street, Changchun 130012, China; \\ E-Mail: wangy2011@jlu.edu.cn \\ 2 State Key Laboratory of Laser Interaction with Matter, Changchun Institute of Optics, Fine \\ Mechanics and Physics, Chinese Academy of Science, Changchun 130033, China; \\ E-Mails: guoj@ciomp.ac.cn (J.G.); wtfeng@sina.com (T.W.); shaojunfeng1984@163.com (J.S.); \\ wangd@ciomp.com.cn (D.W.)
}

* Author to whom correspondence should be addressed; E-Mail: ywyang@jlu.edu.cn; Tel.: +86-431-8516-8468.

Academic Editors: Jordi Sort and Eva Pellicer

Received: 18 August 2015 / Accepted: 8 October 2015 / Published: 14 October 2015

\begin{abstract}
Recently, transition metal oxides, such as ruthenium oxide $\left(\mathrm{RuO}_{2}\right)$, manganese dioxide $\left(\mathrm{MnO}_{2}\right)$, nickel oxides $(\mathrm{NiO})$ and cobalt oxide $\left(\mathrm{Co}_{3} \mathrm{O}_{4}\right)$, have been widely investigated as electrode materials for pseudo-capacitors. In particular, these metal oxides with mesoporous structures have become very hot nanomaterials in the field of supercapacitors owing to their large specific surface areas and suitable pore size distributions. The high specific capacities of these mesoporous metal oxides are resulted from the effective contacts between electrode materials and electrolytes as well as fast transportation of ions and electrons in the bulk of electrode and at the interface of electrode and electrolyte. During the past decade, many achievements on mesoporous transition metal oxides have been made. In this mini-review, we select several typical nanomaterials, such as $\mathrm{RuO}_{2}, \mathrm{MnO}_{2}, \mathrm{NiO}, \mathrm{Co}_{3} \mathrm{O}_{4}$ and nickel cobaltite $\left(\mathrm{NiCo}_{2} \mathrm{O}_{4}\right)$, and briefly summarize the recent research progress of these mesoporous transition metal oxides-based electrodes in the field of supercapacitors.
\end{abstract}

Keywords: supercapacitor; pseudo-capacitor; transition metal oxides; specific capacity; mesoporous materials 


\section{Introduction}

Energy crisis and environmental pollution have triggered the development of clean and renewable energy storage systems. Supercapacitors, also called electrochemical capacitors, are a novel type of charge energy storage devices in between traditional capacitors and batteries $[1,2]$. Compared with traditional capacitors, supercapacitors possess higher specific capacity and specific energy. Meanwhile, they exhibit higher specific power, shorter charging time, more efficient discharging than batteries, and they cause no pollution in the environment [3]. Although their energy density is 10 to 50 times lower than lithium ion batteries now, supercapacitors with a near unlimited cycle life are useful in the fields of power system, memory storage, and vehicle assistant equipment (Figure 1). For example, combining a supercapacitor and a battery in a single unit can create an electric vehicle with longer life, lower costs and more power. Based on the principle of energy storage, supercapacitors can be classified into electric double layer capacitors (EDLCs) and pseudo-capacitors [4]. EDLCs store charges using the very thin double layer structure formed at the interface between electrode and electrolyte, while pseudo-capacitors use fast and reversible redox reactions on the surface and bulk near the surface of electrodes for energy storage. Compared with EDLCs, pseudo-capacitors exhibit higher capacitance and higher energy density [4-6].

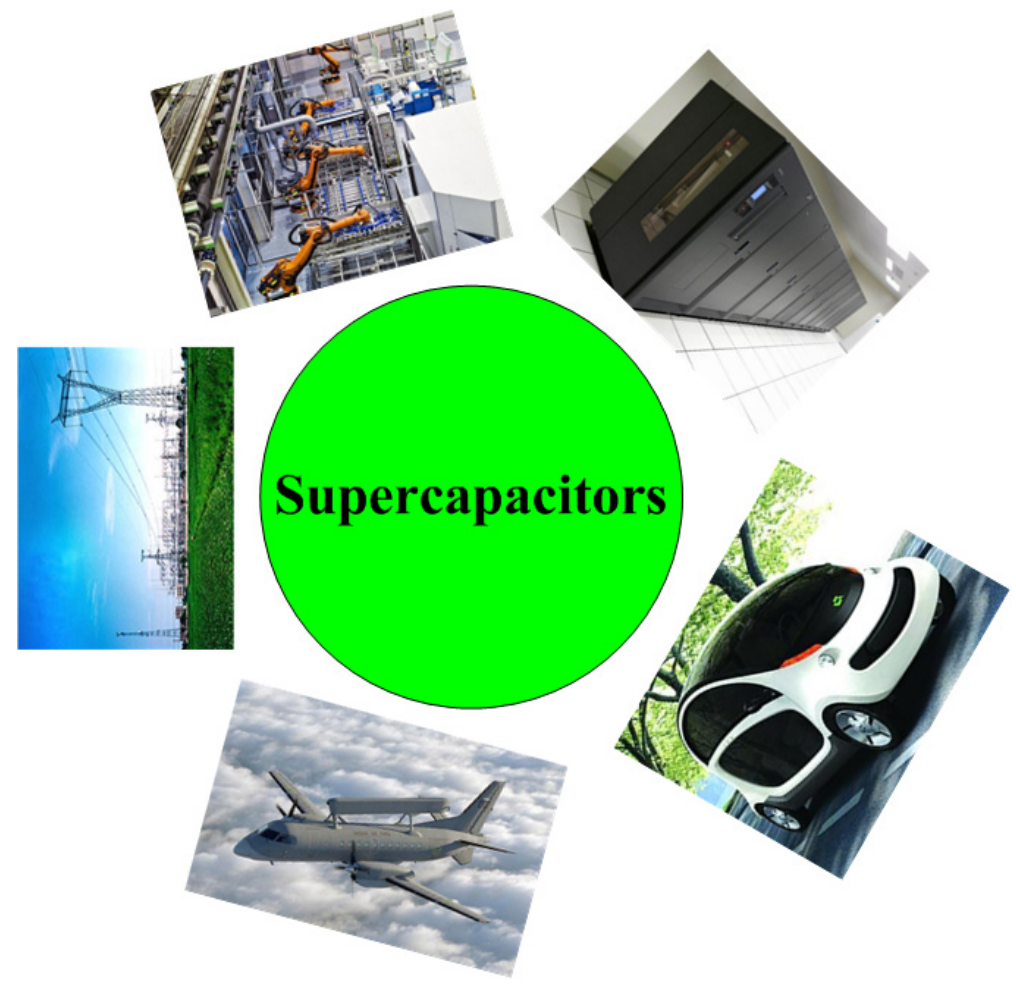

Figure 1. Some possible applications of supercapacitors in today's society.

Nanoporous carbons are considered as one kind of ideal electrode materials for the EDLCs due to their large surface area, controlled pore structure, and high conductivity [7-9]. While for pseudo-capacitors, transition metal oxides as well as conducting polymers are common electrode materials [3]. Among them, transition metal oxides, such as ruthenium oxide $\left(\mathrm{RuO}_{2}\right)$, manganese dioxide $\left(\mathrm{MnO}_{2}\right)$, nickel oxides $(\mathrm{NiO})$ and cobalt oxide $\left(\mathrm{Co}_{3} \mathrm{O}_{4}\right)$, are investigated widely as electrodes materials [10-12]; both 
faradaic and non-faradaic mechanisms are involved in charge storage [13-16]. $\mathrm{RuO}_{2}$ involves faradaic charge-transfer reactions, and its cyclic voltammogram (CV) shape is quite broad, exhibiting a quasi-rectangular shape [17]. The good conductivity, rapid proton transport and larger surface area all contribute to rapid and reversible faradaic reactions with high capacitance [18]. Unfortunately, the high cost of $\mathrm{RuO}_{2}$ limits its large-scale applications. Therefore, significant efforts are being focused on finding a promising alternative to $\mathrm{RuO}_{2} . \mathrm{MnO}_{2}, \mathrm{NiO}$, and $\mathrm{Co}_{3} \mathrm{O}_{4}$ are investigated as electrode materials to replace $\mathrm{RuO}_{2} . \mathrm{MnO}_{2}$ possesses low cost and rectangular voltammogram due to fast and reversible faradaic reactions $[19,20]$, which is taken as one of the promising alternatives to $\mathrm{RuO}_{2}$. $\mathrm{NiO}$, and $\mathrm{Co}_{3} \mathrm{O}_{4}$ are battery materials in the bulk state. When storage sites are limited on the surface of materials through nanostructure, significant pseudo-capacitance emerges [17]. Moreover, nickel cobaltite $\left(\mathrm{NiCo}_{2} \mathrm{O}_{4}\right)$ also exhibits high capacitance values at short charge-discharge times recently, and redox behaviors of both nickel and cobalt are involved in energy storage [21,22]. Herein, $\mathrm{RuO}_{2}, \mathrm{MnO}_{2}, \mathrm{NiO}$, $\mathrm{Co}_{3} \mathrm{O}_{4}$ and $\mathrm{NiCo}_{2} \mathrm{O}_{4}$ are specially selected, and their roles in supercapacitors will be reviewed.

A supercapacitor consists of electrode, electrolyte and separator, where electrode plays a key role for the performance of supercapacitor. It is a crucial task to explore electrode materials with excellent performance. According to the work principle of pseudo-capacitors, electrode materials and electrolyte should contact effectively, meanwhile, ions/charges should transport fast in the bulk of electrode and at the interface between electrode and electrolyte in order to achieve excellent properties. Therefore, transition metal oxides with mesopores (between 2 and $50 \mathrm{~nm}$ ) are favorable for building supercapacitors with high performance due to their large specific surface area and suitable pore size distribution [23]. During the past decade, mesoporous $\mathrm{RuO}_{2}, \mathrm{MnO}_{2}, \mathrm{NiO}, \mathrm{Co}_{3} \mathrm{O}_{4}$, and $\mathrm{NiCo}_{2} \mathrm{O}_{4}$ have been widely studied for supercapacitors. The simple and effective synthetic routes were developed, the nanomaterials with different morphologies were prepared, and the specific capacity and stability of devices were significantly improved. In this review, we briefly summarize the recent progress on these mesoporous transition metal oxide-based electrodes in the field of supercapacitors.

\section{Transition Metal Oxides for Pseudo-Capacitors}

\subsection{Ruthenium Oxide $\left(\mathrm{RuO}_{2}\right)$ for Pseudo-Capacitors}

$\mathrm{RuO}_{2}$ is known as the best electrode material due to its large specific capacitance $\left(700 \mathrm{~F} \cdot \mathrm{g}^{-1}\right)$, low resistivity, high chemical and thermal stability $[18,24,25]$. When $\mathrm{RuO}_{2}$ is used as an electrode material, a series of redox processes occur, resulting in the variation of oxidation state among $\mathrm{Ru}^{4+}, \mathrm{Ru}^{3+}$ and $\mathrm{Ru}^{2+}$, where pseudo-capacitance mainly contributes to capacitance. Another feature is that these redox processes of $\mathrm{RuO}_{2}$ are reversible. These unique electrochemical features result in quasi-rectangular shape CV curve (Figure 2). Due to these remarkable advantages, $\mathrm{RuO}_{2}$, especially mesoporous $\mathrm{RuO}_{2}$, has attracted much attention from scientific community and industry. Until now, several different routes have been developed for the synthesis of mesoporous $\mathrm{RuO}_{2}$. For example, Galizzioli and Rochefort synthesized $\mathrm{RuO}_{2}$ by thermal decomposition of $\mathrm{RuCl}_{3}$ on metallic supports in solutions of electrolytes [26,27]. Zheng et al. prepared hydrous $\mathrm{RuO}_{2}$ by a sol-gel process and obtained specific capacitance as high as $720 \mathrm{~F} \cdot \mathrm{g}^{-1}$ for a powder formed at $150{ }^{\circ} \mathrm{C}$ [18]. This is the highest specific capacitance for $\mathrm{RuO}_{2}$. In addition, Liu et al. prepared $\mathrm{RuO}_{2}$ films by thermal and 
electrochemical methods [28]. Dubala and coworkers reported a surfactant-less and binder-free chemical bath deposition method to synthesize $\mathrm{RuO}_{2}$ thin films [29]. Although $\mathrm{RuO}_{2}$ has large specific capacitance, it is difficult to use $\mathrm{RuO}_{2}$ in real application, considering its very high cost and environmental toxicity. These limitations can be partly overcome by hybridization of $\mathrm{RuO}_{2}$ with other common conductive materials. For instance, $\mathrm{NiO} / \mathrm{RuO}_{2}$ composite materials were prepared and a maximum specific capacitance of $210 \mathrm{~F} \cdot \mathrm{g}^{-1}$ was obtained for composite electrode with $10 \mathrm{wt} \% \mathrm{RuO}_{2}$ in the voltage range of -0.4 to $0.5 \mathrm{~V}$ in $1 \mathrm{M} \mathrm{KOH}$ solution [30]. $\mathrm{SnO}_{2} / \mathrm{RuO}_{2}$ composite films were prepared by chemical bath deposition method. The specific capacitance of $150 \mathrm{~F} \cdot \mathrm{g}^{-1}$ was obtained by optimizing synthetic conditions [31]. $\mathrm{RuO}_{2}$ /polyaniline electrodes were prepared by electrodeposition, revealing a specific capacitance of $474 \mathrm{~F} \cdot \mathrm{g}^{-1}$ and a small charge transfer resistance of $2.24 \Omega$ [32]. $\mathrm{RuO}_{2} / \mathrm{TiO}_{2}$ nanotubes composites were synthesized by loading various amounts of $\mathrm{RuO}_{2}$ on $\mathrm{TiO}_{2}$ nanotubes and a maximum specific capacitance of $1263 \mathrm{~F} \cdot \mathrm{g}^{-1}$ was obtained [33]. By using carbon fibre paper as a support for $\mathrm{RuO}_{2}$, a specific capacitance of $977 \mathrm{~F} \cdot \mathrm{g}^{-1}$ was also obtained in a supercapacitor with $1 \mathrm{M} \mathrm{H}_{2} \mathrm{SO}_{4}$ as electrolyte [34]. The special capacitances of these hybrid materials are summarized in Table 1.

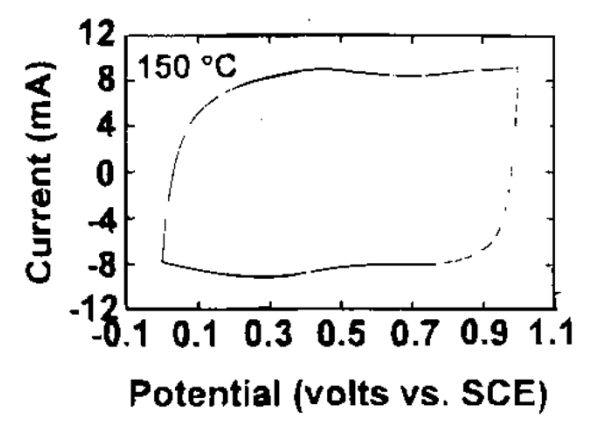

Figure 2. Cyclic voltammogram $(\mathrm{CV})$ of $\mathrm{RuO}_{2} \cdot x \mathrm{H}_{2} \mathrm{O}$ electrodes annealed at $150{ }^{\circ} \mathrm{C}$. The voltage scan rate was $2 \mathrm{mV} \cdot \mathrm{s}^{-1}$, and the electrolyte was $0.5 \mathrm{M}$ of $\mathrm{H}_{2} \mathrm{SO}_{4}$ [18].

Table 1. The special capacitances of hybrid $\mathrm{RuO}_{2}$ materials.

\begin{tabular}{cc}
\hline Materials & Special Capacitance $\left(\mathbf{F} \cdot \mathbf{g}^{-1}\right)$ \\
\hline $\mathrm{RuO}_{2}$ & $720[18]$ \\
$\mathrm{NiO}_{2} / \mathrm{RuO}_{2}$ & $210[30]$ \\
$\mathrm{SnO}_{2} / \mathrm{RuO}_{2}$ & $150[31]$ \\
$\mathrm{RuO}_{2} / \mathrm{Polyaniline} \mathrm{RuO}_{2} / \mathrm{TiO}_{2}$ & $474[32]$ \\
$\mathrm{RuO}_{2} / \mathrm{Carbon} \mathrm{fibre} \mathrm{paper}$ & $1263[33]$ \\
\hline
\end{tabular}

\subsection{Manganese Dioxide $\left(\mathrm{MnO}_{2}\right)$ for Pseudo-Capacitors}

$\mathrm{MnO}_{2}$ has been taken as a promising alternative to $\mathrm{RuO}_{2}$ because of its low cost and superior electrochemical performance [19,20,35,36]. Generally, capacitance properties of $\mathrm{MnO}_{2}$ are investigated in $\mathrm{Na}_{2} \mathrm{SO}_{4}$ electrolyte. In $\mathrm{Na}_{2} \mathrm{SO}_{4}$ electrolyte, reversible transitions of $\mathrm{MnO}_{2} \leftrightarrow \mathrm{MnOONa}$ occur, which is responsible for pseudo-capacitance properties [19,20]. The rectangular voltammogram implies fast and reversible capacitive behaviors, which, together with excellent cycle stability of $\mathrm{MnO}_{2}$, were demonstrated from the linearship of galvanostatic charge/discharge (GCD) profiles (Figure 3). According 
to theoretical calculation, specific capacitance of $\mathrm{MnO}_{2}$ is up to $1100 \mathrm{~F} \cdot \mathrm{g}^{-1}$ over a potential window of $1.0 \mathrm{~V}$. However, the specific capacitances from experiments were five or ten times lower than theoretical values [37-41]. Both crystallographic forms (such as $\alpha, \beta, \gamma, \delta, \lambda$, etc.) and morphological nature are contributed to the low specific capacitance [37]. In order to obtain $\mathrm{MnO}_{2}$ with high specific capacitance, much effort has been devoted to the synthesis of mesoporous $\mathrm{MnO}_{2}$. Template method, microemulsion method, hydrothermal method, sonochemical method and ultrasound irradiation have been utilized to synthesize mesoporous $\mathrm{MnO}_{2}$ [38-41]. For example, semicrystalline gyroidal mesoporous $\mathrm{MnO}_{2}$ was prepared by using mesoporous silica KIT-6 as hard template, and stable reversible electrochemical behavior with capacitance of $220 \mathrm{~F} \cdot \mathrm{g}^{-1}$ in a potential range of $-0.1-0.55 \mathrm{~V}$ was observed [38]. Mesoporous $\mathrm{MnO}_{2}$ nanoparticles with 4-5 nm of pore size were synthesized by a soft template method, and specific capacitance of $297 \mathrm{~F} \cdot \mathrm{g}^{-1}$ was obtained at a high loading level of $1.55 \mathrm{mg} \cdot \mathrm{cm}^{-2}$ [39]. Mesoporous $\mathrm{MnO}_{2}$ with 2-20 nm of average pore sizes were obtained in sonochemical method from $\mathrm{KMnO}_{4}$ by using a tri-block copolymer (P123) as a soft template, and a maximum specific capacitance of $265 \mathrm{~F} \cdot \mathrm{g}^{-1}$ was obtained (Figure 4a,b) [40]. Mesoporous $\mathrm{MnO}_{2}$ with specific surface area of $192 \mathrm{~m}^{2} \cdot \mathrm{g}^{-1}$ and $10 \mathrm{~nm}$ of pore distribution was synthesized through the reaction of potassium permanganate and ethanol under ultrasound irradiation (Figure 4c,d). The specific capacitance of $229 \mathrm{~F} \cdot \mathrm{g}^{-1}$ and the specific capacitance retention of $97.3 \%$ after 2000 cycles were obtained [19]. Birnessite-type mesoporous $\mathrm{MnO}_{2}$ nanospheres were synthesized by the microwave-hydrothermal method, and the electrochemical test showed that the specific capacitance was $210 \mathrm{~F} \cdot \mathrm{g}^{-1}$ at $200 \mathrm{~mA} \cdot \mathrm{g}^{-1}$ in $1.0 \mathrm{M} \mathrm{Na}_{2} \mathrm{SO}_{4}$ electrolyte with the specific capacitance retention and columbic efficiency of over $96 \%$ and $98 \%$, respectively, after 300 cycles at $1.6 \mathrm{~A} \cdot \mathrm{g}^{-1}[41]$.
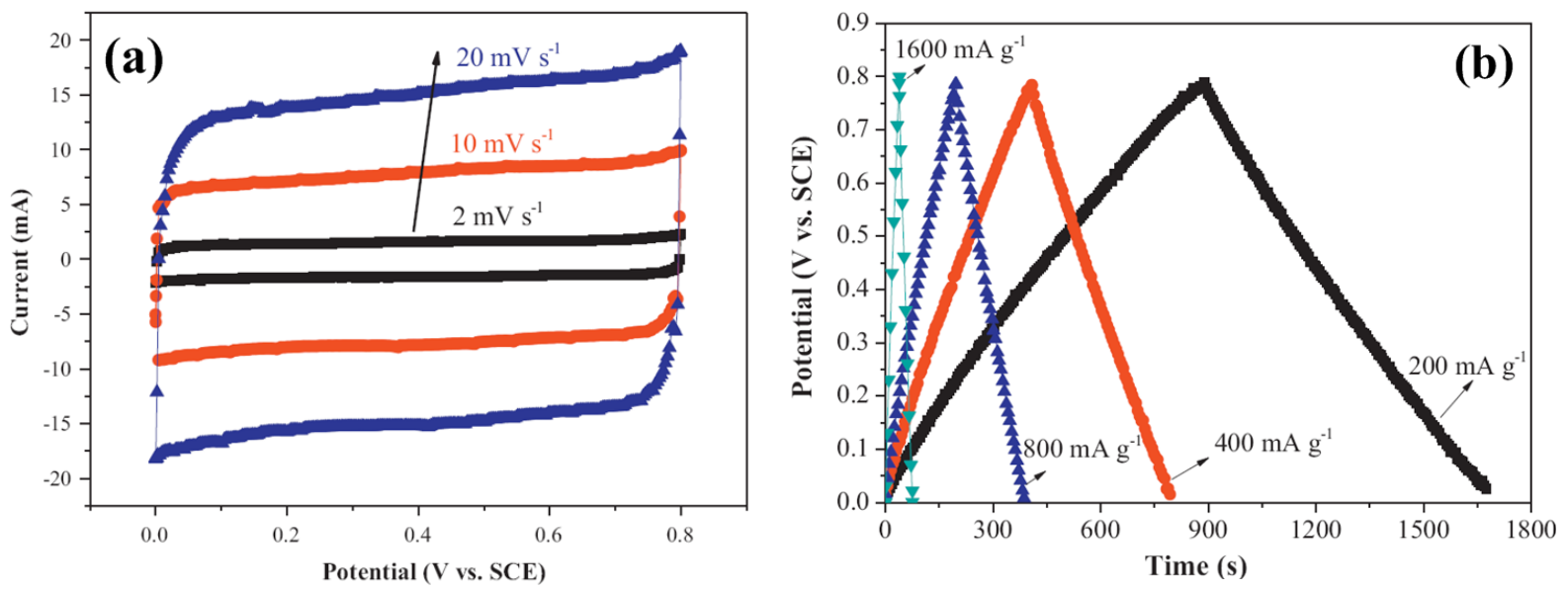

Figure 3. (a) $\mathrm{CVs}$ of $\mathrm{MnO}_{2}$ at scan rates of 2,10 , and $20 \mathrm{mV} \cdot \mathrm{s}^{-1}$; and (b) Galvanostatic charge/discharges (GCDs) of $\mathrm{MnO}_{2}$ at current densities of $200,400,800$, and $1600 \mathrm{~mA} \cdot \mathrm{g}^{-1}$ [41]. 

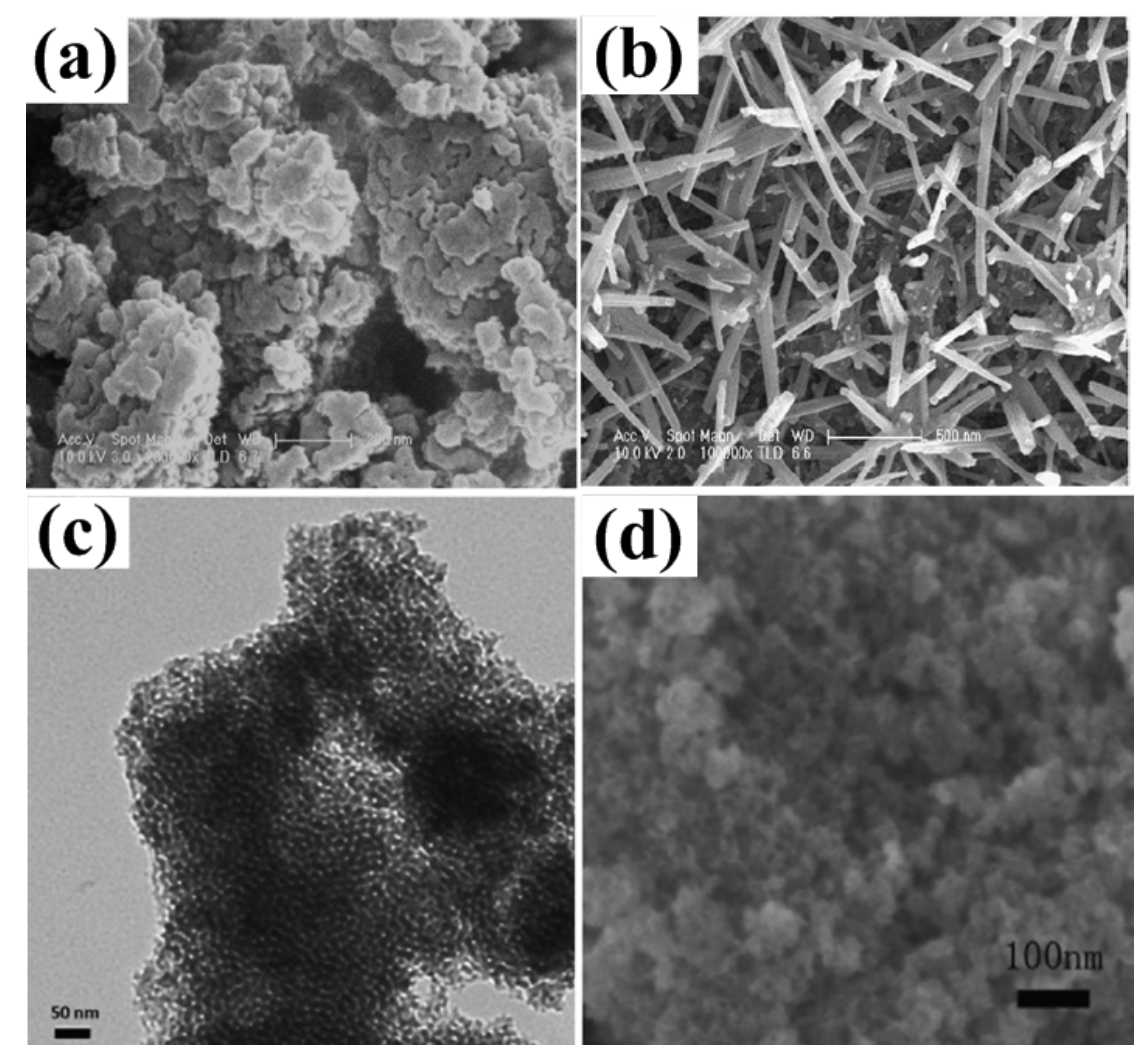

Figure 4. Scanning electron microscopy (SEM) images of $\mathrm{MnO}_{2}$ samples synthesized by sonochemical method with two different amplitudes: (a) $30 \mu \mathrm{m}$; (b) $60 \mu \mathrm{m}$ [34]. Transmission electron microscope (TEM) (c) and SEM (d) images of mesoporous $\mathrm{MnO}_{2}$ synthesized through the reaction of potassium permanganate and ethanol under ultrasound irradiation [19].

\subsection{Nickel Oxide (NiO) for Pseudo-Capacitors}

$\mathrm{NiO}$ is regarded as a promising pseudo-capacitor material due to its high theoretical capacitance value of $2573 \mathrm{~F} \cdot \mathrm{g}^{-1}$, low cost and distinct redox [42]. For NiO, the variation of oxidation state of $\mathrm{Ni}$ is still not very clear. The reaction, $\mathrm{NiO}+\mathrm{OH} \leftrightarrow \mathrm{NiOOH}+\mathrm{e}^{-}$, is usually believed to occur first. Then, the oxyhydroxide participates in the following reversible redox processes [17]. There are still some issues to be solved for the practical applications of $\mathrm{NiO}$ in supercapacitors. Among them, the significantly lower specific capacitance than theoretical value is one of the main issues. Due to the tight correlation between electrochemical performance of $\mathrm{NiO}$ and its porosity and surface area, most of the recent works are focused on the synthetic method and morphology study of materials. It has been known that mesoporous structured transition metal oxides are favorable for specific capacitance. On one hand, large specific surface is beneficial for electrolytes to access the electrochemically active sites. On the other hand, the mesoporous pore size is profitable for fast redox process. For the preparation of $\mathrm{NiO}$ with mesoporous structures, several methods have been employed. For example:

(1) $\mathrm{Ni}(\mathrm{OH})_{2} \rightarrow \mathrm{NiO}:$ Wu et al. prepared highly porous $\mathrm{NiO}$ via a combination of sol-gel process with supercritical drying method [5]. They prepared aerogel-like $\mathrm{Ni}(\mathrm{OH})_{2}$ samples and then heated them to achieve aerogel-like $\mathrm{NiO}$. The as-synthesized $\mathrm{NiO}$ samples exhibited $80 \%-90 \%$ of porosity and $180.5-325.6 \mathrm{~m}^{2} \cdot \mathrm{g}^{-1}$ of surface area. The average specific capacitance was observed to be $c a$. $75-125 \mathrm{~F} \cdot \mathrm{g}^{-1}$ 
between a potential window of $0-0.35 \mathrm{~V}$ vs. SCE [5]. Yuan and coworkers synthesized $\beta-\mathrm{Ni}(\mathrm{OH})_{2}$ microspheres by using coalescence and Ostwald-ripening mechanisms, and then these $\beta-\mathrm{Ni}(\mathrm{OH})_{2}$ microspheres were calcinated to produce hierarchical porous $\mathrm{NiO}$ microsphere (Figure 5a-d) [41]. Electrochemical data demonstrated that the hierarchical porous $\mathrm{NiO}$ nano/micro superstructures were capable of delivering a specific capacitance of $710 \mathrm{~F} \cdot \mathrm{g}^{-1}$ at $1 \mathrm{~A} \cdot \mathrm{g}^{-1}$ and offered a specific capacitance retention of $c a$. $98 \%$ after 2000 continuous charge-discharge cycles [43]. Lee et al. applied hexamethylenetetramine hydrolysis to synthesize $\mathrm{Ni}(\mathrm{OH})_{2}$ microstructures, followed by calcination to produce $\mathrm{NiO}$ microstructures at high temperature. The specific capacitance of fabricated $\mathrm{NiO}$ at 2,5 , 10 , and $20 \mathrm{mV} \cdot \mathrm{s}^{-1} \mathrm{scan}$ rate was $718,470,420$, and $403 \mathrm{~F} \cdot \mathrm{g}^{-1}$, respectively. The $\mathrm{NiO}$ microstructures had good retention for more than 1000 cycles in a cycling test [44].

(2) Hydrothermal Method: Li et al. used hydrothermal route to synthesize $\mathrm{Ni}(\mathrm{OH})_{2}$, and then prepared various mesoporous $\mathrm{NiO}$ hierarchical microspheres via thermal decomposition of $\mathrm{Ni}(\mathrm{OH})_{2}$ in air [45]. Electrochemical data demonstrated that the mesoporous $\mathrm{NiO}$ network-like hierarchical microspheres could deliver a specific capacitance of $555 \mathrm{~F} \cdot \mathrm{g}^{-1}$ at $2 \mathrm{~A} \cdot \mathrm{g}^{-1}$, and $390 \mathrm{~F} \cdot \mathrm{g}^{-1}$ even at a current density of $10 \mathrm{~A} \cdot \mathrm{g}^{-1}$ [45]. Yang et al. prepared mesoporous slit-structured $\mathrm{NiO}$ materials through a hydrothermal route with sodium dodecyl benzene sulfonate (SDBS) as an additive (Figure $5 \mathrm{e}-\mathrm{f}$ ). The as-prepared $\mathrm{NiO}$ samples presented specific capacitance of over $1700 \mathrm{~F} \cdot \mathrm{g}^{-1}$ in the potential range from 0.10 to $0.56 \mathrm{~V}$ at a constant current of $2 \mathrm{~A} \cdot \mathrm{g}^{-1}$, and capacitance retention of $90 \%$ after 1000 continuous charge-discharge cycles [46].

(3) Template Method: Mesoporous NiO was synthesized by a hydrothermal homogeneous precipitation method using mixed anionic/non-ionic surfactants as template. The electrochemical results showed that the as-prepared mesoporous $\mathrm{NiO}$ sample had a specific capacitance of $268 \mathrm{~F} \cdot \mathrm{g}^{-1}$ [47]. A nanospherical porous $\mathrm{NiO}$ electrode material was prepared by using porous carbon nanospheres as a hard template (Figure $5 \mathrm{~g}-\mathrm{j}$ ). The GCD measurements demonstrated that the optimal electrode possessed a specific capacitance of $1201 \mathrm{~F} \cdot \mathrm{g}^{-1}$ at a discharge current density of $0.5 \mathrm{~A} \cdot \mathrm{g}^{-1}$ and cycling stability of $70 \%$ capacity retention after 500 continuous charge/discharge cycles [48].

(4) Microwave Assisted Heating Method: Meher et al. prepared porous NiO by microwave assisted heating method under homogeneous precipitation conditions [49]. Compared with that from the traditional reflux method, the sample prepared from microwave method showed higher rate specific capacitance $\left(370 \mathrm{~F} \cdot \mathrm{g}^{-1}\right)$ in the charge-discharge measurements made at a discharge current of $2 \mathrm{~A} \cdot \mathrm{g}^{-1}[49]$.

(5) Sol-Gel Method: NiO nanostructures with three distinct morphologies were fabricated by a sol-gel method, and nanoflower-shaped $\mathrm{NiO}$ with a distinctive three-dimensional (3D) network showed good supercapacitor properties [50].

Another obstacle to specific capacitance of $\mathrm{NiO}$ is its poor conductivity, which results in low electron transport. To enhance electrochemical activity of the electrode, the dopants, such as transition and non-transition metal ions, have been introduced into the lattices of metal oxides. For instance, $\mathrm{La}^{3+}$ doped $\mathrm{NiO}$ microspheres with porous structures were fabricated using colloidal carbon spheres as hard template via a hydrothermal method followed by a calcination process. As a result, $1.5 \mathrm{~mol} \% \mathrm{La}^{3+}$ doped $\mathrm{NiO}$ showed a remarkable specific capacitance of $253 \mathrm{~F} \cdot \mathrm{g}^{-1}$ (two times higher than that of the pure $\mathrm{NiO}$ ) and good cycling stability (34\% capacity increase after 500 cycles) (Figure 6) [51]. 

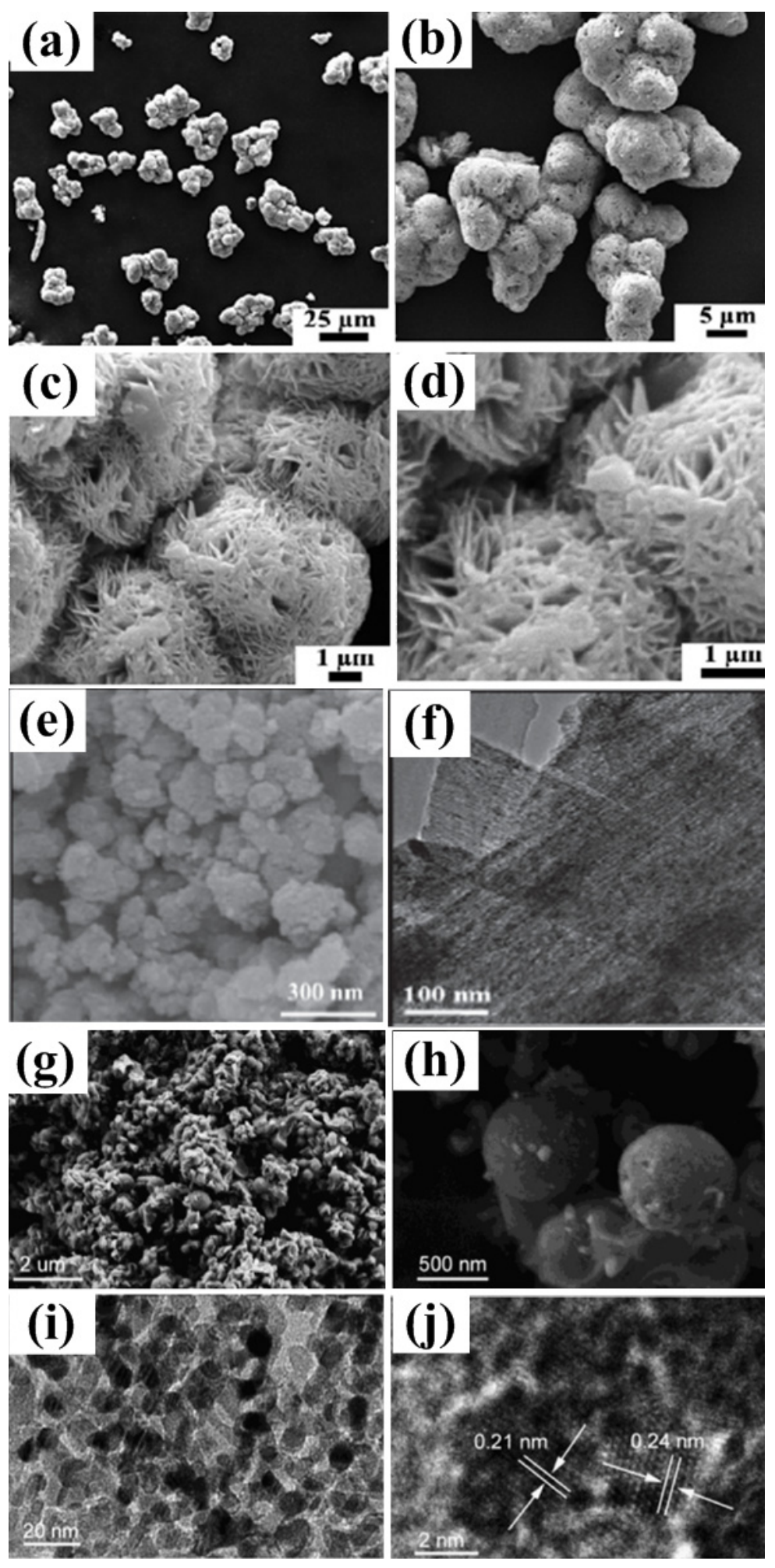

Figure 5. SEM images of the synthesized $\mathrm{NiO}$ microspheres (obtained by thermal decomposition of the $\mathrm{Ni}(\mathrm{OH})_{2}$ precursor after refluxing treatment for $60 \mathrm{~min}$ ) at different magnifications (a-d) [43]. (e) SEM and (f) high resolution transmission electron microscopy (HRTEM) images of the NiO sample synthesized via a hydrothermal route with sodium dodecyl benzene sulfonate (SDBS) as an additive [46]. SEM images (g,h) at different magnifications, and TEM (i) and HRTEM (j) images of NiO sample prepared by using porous carbon nanospheres as a hard template [48]. 


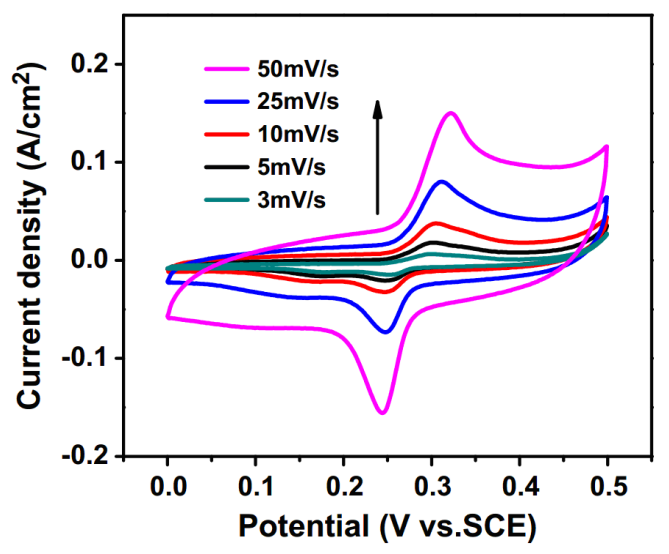

Figure 6. $\mathrm{CVs}$ of $1.50 \mathrm{~mol} \% \mathrm{La}^{3+}$-doped $\mathrm{NiO}$ electrode measured at scan rates from 3 to $50 \mathrm{mV} \cdot \mathrm{s}^{-1}[51]$.

There are also some reports on the synthesis of $\mathrm{NiO} /$ conductive materials. For example, monolithic $\mathrm{NiO} / \mathrm{Ni}$ nanocomposite electrodes were fabricated recently, and the maximum capacitance was $910 \mathrm{~F} \cdot \mathrm{g}^{-1}$ due to the highly activated $\mathrm{NiO}$ surface layer and the conductive network of metal cores [52]. Flower-shaped $\mathrm{NiO} / \alpha-\mathrm{Ni}(\mathrm{OH})_{2}$ hybrid structures were synthesized by a solvothermal process. The hybrid composite demonstrates a solid capacitance value of $707 \mathrm{~F} \cdot \mathrm{g}^{-1}$ at $2 \mathrm{~A} \cdot \mathrm{g}^{-1}$ and $474 \mathrm{~F} \cdot \mathrm{g}^{-1}$ at a high discharge rate of $10 \mathrm{~A} \cdot \mathrm{g}^{-1}$. In order to further improve the performance and the capacitance retention, conductive carbon nanomaterials were used as supports for the $\mathrm{NiO} / \alpha-\mathrm{Ni}(\mathrm{OH})_{2}$ hybrid and it was found that single-walled carbon nanotubes significantly enhanced the performance of composite to $810 \mathrm{~F} \cdot \mathrm{g}^{-1}$ at a high current discharge of $10 \mathrm{~A} \cdot \mathrm{g}^{-1}[42]$.

\subsection{Cobalt Oxide $\left(\mathrm{Co}_{3} \mathrm{O}_{4}\right)$ for Pseudo-Capacitors}

$\mathrm{Co}_{3} \mathrm{O}_{4}$ has low environmental toxicity and high specific capacitance of $3560 \mathrm{~F} \cdot \mathrm{g}^{-1}$ in theory, and is of low cost $[53,54]$. During electrochemical processes, both pseudocapacitive behavior $(\mathrm{CoOOH}$ $\left.+\mathrm{OH}^{-} \leftrightarrow \mathrm{CoO}_{2}+\mathrm{H}_{2} \mathrm{O}+\mathrm{e}^{-}\right)$and battery-type behavior $\left(\mathrm{Co}_{3} \mathrm{O}_{4}+\mathrm{OH}^{-}+\mathrm{H}_{2} \mathrm{O} \leftrightarrow 3 \mathrm{MOOH}+\mathrm{e}^{-}\right)$are contributed to capacitance, which results in high capacitance values $\left(3560 \mathrm{~F} \cdot \mathrm{g}^{-1}\right.$ in theory) $[17,53,54]$. However, the specific capacitances from real devices are much lower than that from theory. Electron effective transportation and ion fast diffusion would result in high performance of supercapacitors. Therefore, much effort has been devoted to synthesizing $\mathrm{Co}_{3} \mathrm{O}_{4}$ with appropriate nanostructures, particularly, $\mathrm{Co}_{3} \mathrm{O}_{4}$ nanomaterials with mesoporous structures, to improve the electron and ion transportation in electrodes and at the interface between electrode and electrolyte in supercapacitor devices $[55,56]$. For example, mesoporous nanocrystalline $\mathrm{Co}_{3} \mathrm{O}_{4}$ with a particle diameter of $c a .3 \mathrm{~nm}$ was synthesized based on strong chemical coordination interactions between $\mathrm{Co}^{2+}$ in solution and amino groups in the polyacrylamide template, and capacitance of $401 \mathrm{~F} \cdot \mathrm{g}^{-1}$ was obtained from these prerequisites [57]. Mesoporous $\mathrm{Co}_{3} \mathrm{O}_{4}$ microspheres with crater-like morphology were obtained by utilizing the mesoporous silica material named MCM-41 as a template. This material provided a specific capacitance of $102 \mathrm{~F} \cdot \mathrm{g}^{-1}$ and capacity retention of $74 \%$ in 500 continuous cycles test at a sweep rate of $3 \mathrm{mV} \cdot \mathrm{s}^{-1}$ [58]. Hierarchically porous $\mathrm{Co}_{3} \mathrm{O}_{4}$ film was prepared by electrodeposition via liquid crystalline template, and specific capacitances of these $\mathrm{Co}_{3} \mathrm{O}_{4}$ films were $443 \mathrm{~F} \cdot \mathrm{g}^{-1}$ at $2 \mathrm{~A} \cdot \mathrm{g}^{-1}$ and $334 \mathrm{~F} \cdot \mathrm{g}^{-1}$ at $40 \mathrm{~A} \cdot \mathrm{g}^{-1}$, respectively [59]. Ultrafine nanosized $\mathrm{Co}_{3} \mathrm{O}_{4}$ materials with interconnected 
macroporous and mesoporous structure were synthesized through sol-gel method, followed by freeze-drying. The specific capacitance of the $\mathrm{Co}_{3} \mathrm{O}_{4}$ material was $742.3 \mathrm{~F} \cdot \mathrm{g}^{-1}$ at a scan rate of $5 \mathrm{mV} \cdot \mathrm{s}^{-1}$ and the capacity retention was $86.2 \%$ after 2000 cycles [60]. With the assistance of mesoporous carbon nanorods, $\mathrm{Co}_{3} \mathrm{O}_{4}$ nanocubes with uniform diameter and high crystallinity were obtained. After calcination, mesoporous $\mathrm{Co}_{3} \mathrm{O}_{4}$ nanocubes were formed. Electrochemical tests revealed that the specific capacitance of $\mathrm{Co}_{3} \mathrm{O}_{4}$ nanocube electrode is $c a .350 \mathrm{~F} \cdot \mathrm{g}^{-1}$ at the current densities of $0.2 \mathrm{~A}^{\circ} \mathrm{g}^{-1}$ (Figure 7) [61]. In addition, meosoporous $\mathrm{Co}_{3} \mathrm{O}_{4}$ with other morphologies were also prepared. For example, tubular $\mathrm{Co}_{3} \mathrm{O}_{4}$ was fabricated by biomorphic synthesis route [62], nanosheets $\mathrm{Co}_{3} \mathrm{O}_{4}$ and microspheres $\mathrm{Co}_{3} \mathrm{O}_{4}$ were prepared by an ethanolamine-assisted solvothermal method and sequential thermal decomposition at mospheric pressure [63].
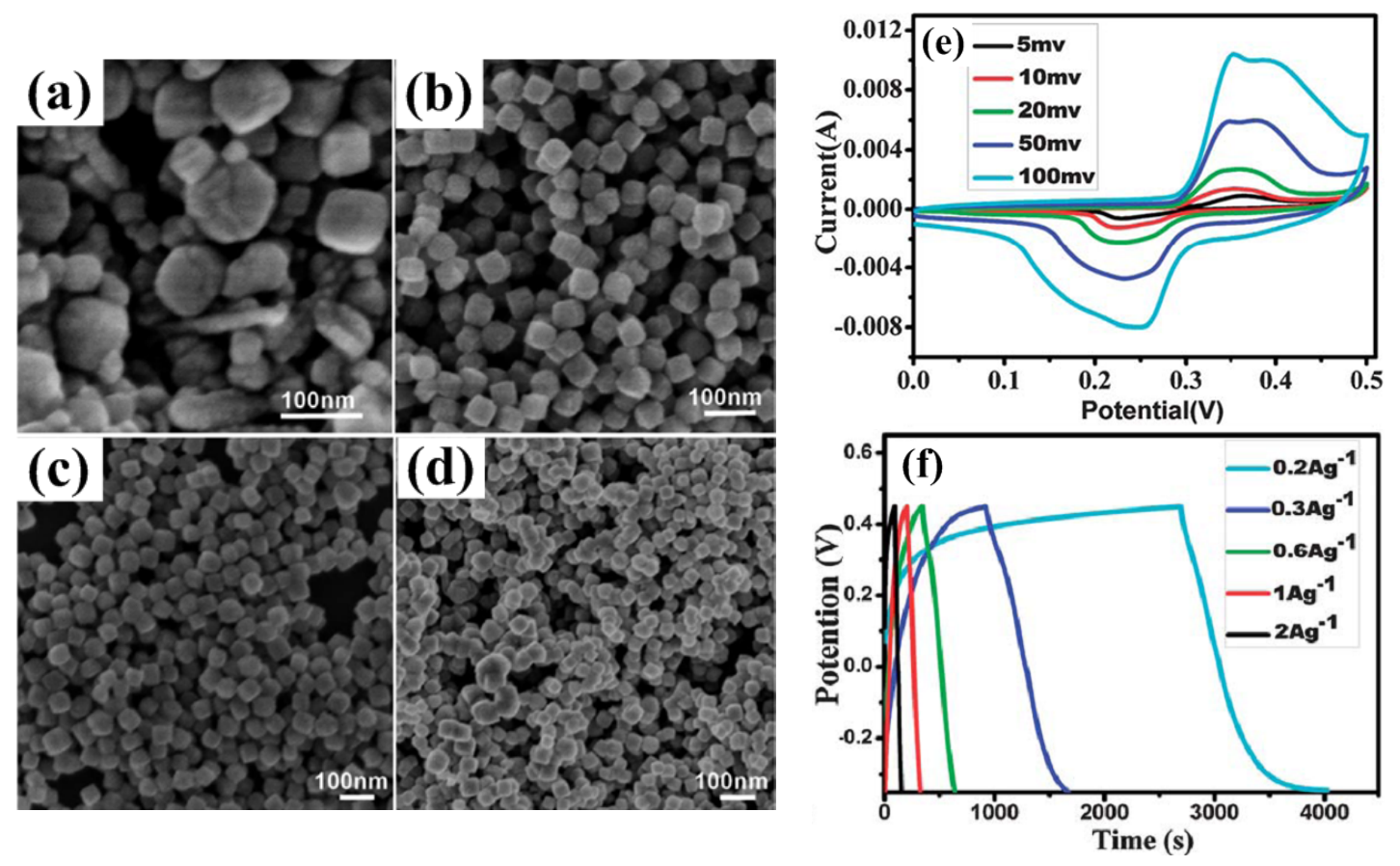

Figure 7. SEM images of $\mathrm{Co}_{3} \mathrm{O}_{4}$ samples obtained by adding different concentrations of mesoporous carbon nanorods: (a) $0 \mathrm{mg} \cdot \mathrm{mL}^{-1}$; (b) $0.0175 \mathrm{mg} \cdot \mathrm{mL}^{-1}$; (c) $0.025 \mathrm{mg} \cdot \mathrm{mL}^{-1}$; (d) $0.05 \mathrm{mg} \cdot \mathrm{mL}^{-1}$. (e) $\mathrm{CV}$ curves of the mesoporous $\mathrm{Co}_{3} \mathrm{O}_{4}$ nanocube electrode at scan rates of $5,10,20,50$ and $100 \mathrm{mV} \cdot \mathrm{s}^{-1}$ and (f) galvanostatic charge/discharge (GCD) curves of the as-prepared electrode at different current densities [61].

In order to simplify the synthetic route and improve the electrochemical performance, mesoporous $\mathrm{Co}_{3} \mathrm{O}_{4}$ was grown on some support materials to form hybrid structures. For example, ultrathin mesoporous $\mathrm{Co}_{3} \mathrm{O}_{4}$ nanosheet arrays were grown on $\mathrm{Ni}$ foam with robust adhesion, which endows fast ion and electron transport, large electroactive surface area, and good structural stability. As a result, superior pseudo-capacitive performance was achieved with ultrahigh specific capacitance in the range of 2735-1471 F.g $\mathrm{g}^{-1}$ and excellent cycling stability up to 3000 cycles (Figure 8) [64]. $\mathrm{Co}_{3} \mathrm{O}_{4}$ was embedded into SBA-15 nanoparticles to form composites by wetness impregnation method (Figure 9). The composite structure improves charged ion transmission inside the channels and the electrochemical utilization of $\mathrm{Co}_{3} \mathrm{O}_{4}$ during the charge/discharge processes. A supercapacitor electrode material based on $\mathrm{Co}_{3} \mathrm{O}_{4}(66 \%) @$ SBA-15 exhibited a maximum specific capacitance of $1086 \mathrm{~F} \cdot \mathrm{g}^{-1}$ in $6 \mathrm{M} \mathrm{KOH}$ 
solution. After 10000 cycles, retention of $90 \%$ of the initial capacitance was observed (Figure 9) [65]. $\mathrm{Co}_{3} \mathrm{O}_{4}$ nanowire/nanoflower hybrid structure on carbon fibre cloth was prepared via a hydrothermal approach followed by thermal treatment in air (Figure 10). A supercapacitor made from this hierarchical hybrid architecture showed a maximum specific capacitance of $4.8 \mathrm{mF} \cdot \mathrm{cm}^{-2}$ at a constant density of $3 \mathrm{~mA} \cdot \mathrm{cm}^{-2}$ in organic electrolyte. In terms of energy and power, the supercapacitor conveyed an energy density of $4.2 \mathrm{~mW} \cdot \mathrm{h} \cdot \mathrm{cm}^{-3}$ with a power density of $1260 \cdot \mathrm{mW} \cdot \mathrm{cm}^{-3}[66]$.
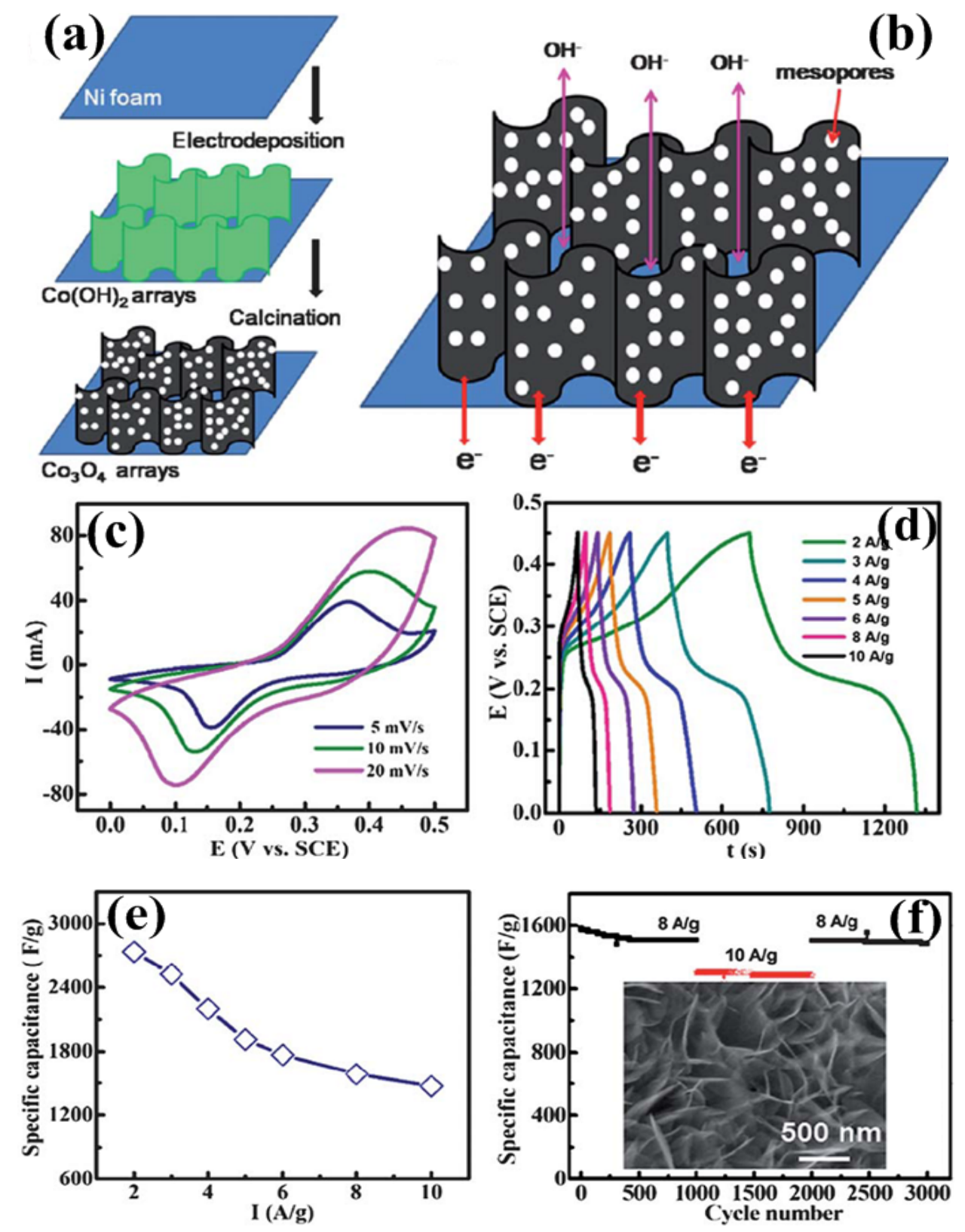

Figure 8. Schematic illustrations of (a) the general electrode design process; and (b) the application advantages of building 2D mesoporous $\mathrm{Co}_{3} \mathrm{O}_{4}$ ultrathin nanosheet arrays on $\mathrm{Ni}$ foam; (c) CV curves; (d) charge-discharge curves; (e) specific capacitance versus current densities; and (f) cycling performance of the $\mathrm{Co}_{3} \mathrm{O}_{4}$ nanosheet arrays/Ni foam electrode at varying current densities. The inset in (f) is field emission scanning electron microscope (FESEM) image of the $\mathrm{Co}_{3} \mathrm{O}_{4}$ nanosheet arrays/Ni foam electrode after cycling [64]. 

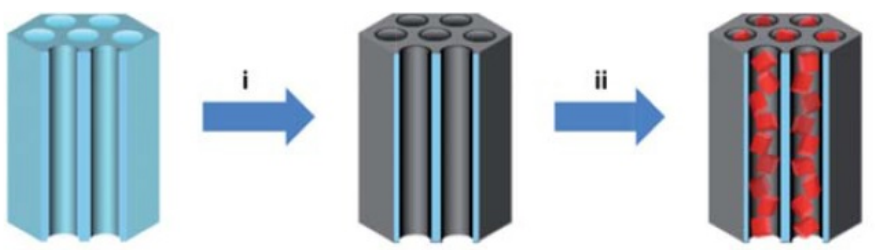

SBA-15 SBA-15 $\mathrm{Co}_{3} \mathrm{O}_{4} @ \mathrm{SBA}-15^{\circ}$

(a)

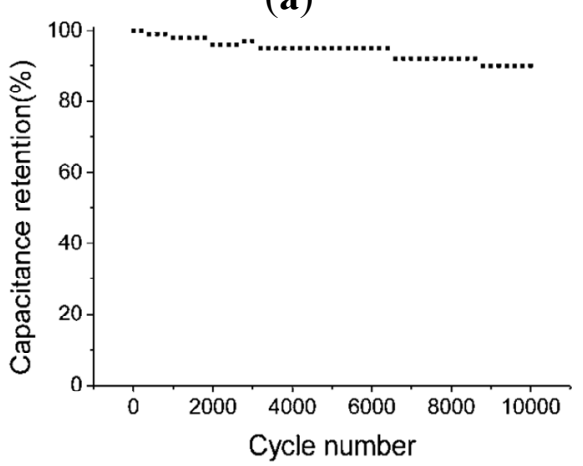

(b)

Figure 9. (a) Illustration of the preparation of $\mathrm{Co}_{3} \mathrm{O}_{4} @$ SBA-15 supercapacitor electrode materials, showing (i) carbon nanomembrane (dark gray) formation on the walls (gray blue) of SBA-15 and (ii) incorporation of $\mathrm{Co}_{3} \mathrm{O}_{4}$ clusters into the cylinder type mesochannels and (b) cycle life of $\mathrm{Co}_{3} \mathrm{O}_{4}(66 \%) @$ SBA-15 electrode material at a scan rate of $0.1 \mathrm{~V} \cdot \mathrm{s}^{-1}[65]$.

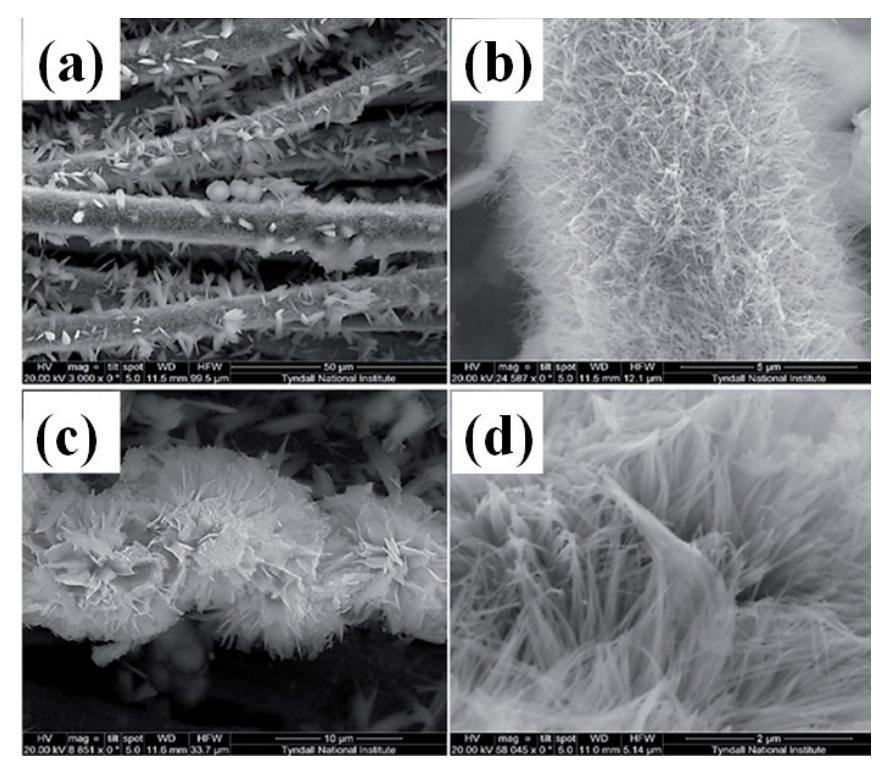

Figure 10. HRSEM images of $\mathrm{Co}_{3} \mathrm{O}_{4}$ nanowire/nanoflower on carbon fibre cloth at different magnifications [66]. (a) and (b) are the low magnification SEM images of bundles of carbon fibers; (c) and (d) are the high magnification SEM images.

\subsection{Nickel Cobaltite (NiCo $\left.2 \mathrm{O}_{4}\right)$ for Pseudo-Capacitors}

From the above discussion, one can see that $\mathrm{NiO}$ and $\mathrm{Co}_{3} \mathrm{O}_{4}$ have attracted wide interest recently in supercapacitor applications due to their high theoretical capacity, abundant structure, good stability 
and low cost. However, in real supercapacitor devices, the observed specific capacitances are still far lower than theoretical values, especially at high rates [67]. A novel compound, $\mathrm{NiCo}_{2} \mathrm{O}_{4}$, attracts researchers' attention. In 2010, Wei et al. obtained its specific capacitance as high as $1400 \mathrm{~F} \cdot \mathrm{g}^{-1}$ at a sweep rate of $25 \mathrm{mV} \cdot \mathrm{s}^{-1}$ in a $1 \mathrm{M} \mathrm{NaOH}$ solution within a potential window of $0.04-0.52 \mathrm{~V}$ [68]. After that, $\mathrm{NiCo}_{2} \mathrm{O}_{4}$ has been extensively investigated for pseudo-capacitors. $\mathrm{NiCo}_{2} \mathrm{O}_{4}$ possesses good electrochemical activity and electrical conductivity at least two orders of magnitude higher than pure $\mathrm{Co}_{3} \mathrm{O}_{4}$ and $\mathrm{NiO}$ [69]. Both nickel and cobalt ions are involved in redox reactions, which is richer than pure nickel oxides and cobalt oxides. The energy storage occurs with reversible transformation of $\mathrm{NiCo}_{2} \mathrm{O}_{4}$ into nickel and cobalt oxyhydroxides as well as the reversible redox reaction of $\mathrm{CoOOH}+$ $\mathrm{OH}^{-} \leftrightarrow \mathrm{CoO}_{2}+\mathrm{H}_{2} \mathrm{O}+\mathrm{e}^{-}$. The theoretical capacity for $\mathrm{NiCo}_{2} \mathrm{O}_{4}$, including the pseudocapacitive and the battery-like faradaic contributions, is $1203 \mathrm{C} \cdot \mathrm{g}^{-1}$ or $2005 \mathrm{~F} \cdot \mathrm{g}^{-1}$ assuming at $0.6 \mathrm{~V}$ potential window in an aqueous alkaline electrolyte [22]. $\mathrm{Up}$ to now, $\mathrm{NiCo}_{2} \mathrm{O}_{4}$ with different structures and morphology, different dimensions have been reported and their electrochemical performances were improved greatly. For example, one-dimensional (1D) ultralayered mesoporous $\mathrm{NiCo}_{2} \mathrm{O}_{4}$ nanowires were synthesized by a template-free strategy (Figure 11). The ultralayered mesoporous nanowire electrode exhibited specific capacitance of $401 \mathrm{~F} \cdot \mathrm{g}^{-1}$ at $1 \mathrm{~A} \cdot \mathrm{g}^{-1}$ and excellent cycling stability (only $c a .10 \%$ loss after 5000 cycles) [70]. Mesoporous $\mathrm{NiCO}_{2} \mathrm{O}_{4}$ nanostructure was synthesized via a D-glucose-assisted solvothermal process. Electrochemical measurements showed that the spinel $\mathrm{NiCo}_{2} \mathrm{O}_{4}$ nanostructure heated at $300{ }^{\circ} \mathrm{C}$ exhibited maximum specific capacitances of $524 \mathrm{~F} \cdot \mathrm{g}^{-1}$ at $0.5 \mathrm{~A} \cdot \mathrm{g}^{-1}$ and $419 \mathrm{~F} \cdot \mathrm{g}^{-1}$ at $10 \mathrm{~A} \cdot \mathrm{g}^{-1}$ with good cycle stability and only $\sim 9 \%$ of capacitance loss after 2500 cycles [71]. Hierarchical mesoporous spinel $\mathrm{NiCo}_{2} \mathrm{O}_{4}$ was synthesized by a hydrothermal method assisted by polyvinylpyrrolidone (PVP) and a post annealing treatment. Compared to conventional flower-like $\mathrm{NiCo}_{2} \mathrm{O}_{4}$, the hierarchical mesoporous structured $\mathrm{NiCo}_{2} \mathrm{O}_{4}$ exhibited better supercapacitance performance. The specific capacitance could reach $1619.1 \mathrm{~F} \cdot \mathrm{g}^{-1}$ at a current density of $2.0 \mathrm{~A} \cdot \mathrm{g}^{-1}$. When the current density was increased to $10.0 \mathrm{~A} \cdot \mathrm{g}^{-1}$, a specific capacitance of $571.4 \mathrm{~F} \cdot \mathrm{g}^{-1}$ could be obtained (Figure 12) [72]. Spinel $\mathrm{NiCo}_{2} \mathrm{O}_{4}$ was synthesized through a thermal decomposition method and specific capacitance was $764 \mathrm{~F} \cdot \mathrm{g}^{-1}$ at $2 \mathrm{mV} \cdot \mathrm{s}^{-1}$ [73]. 3D network-like mesoporous $\mathrm{NiCo}_{2} \mathrm{O}_{4}$ nanostructures were fabricated through a solvothermal route coupled with a post annealing treatment. The as-obtained $\mathrm{NiCo}_{2} \mathrm{O}_{4}$ manifested specific capacitance of $931 \mathrm{~F} \cdot \mathrm{g}^{-1}$ at $3 \mathrm{~A} \cdot \mathrm{g}^{-1}$, capacity retention rate of 85.2 and $72.5 \%$ at 20 and $50 \mathrm{~A} \cdot \mathrm{g}^{-1}$, respectively [74].
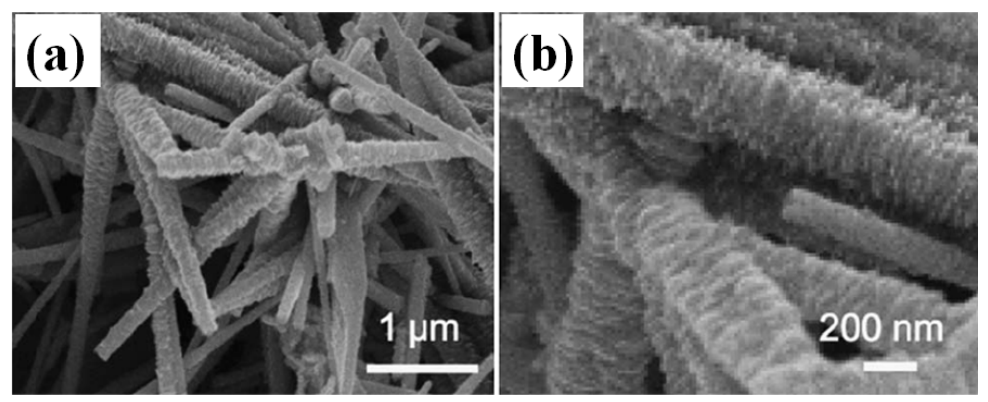

Figure 11. (a) and (b) FESEM images of the as-synthesized ultralayered mesoporous $\mathrm{NiCo}_{2} \mathrm{O}_{4}$ nanowires at different magnifications [70]. 


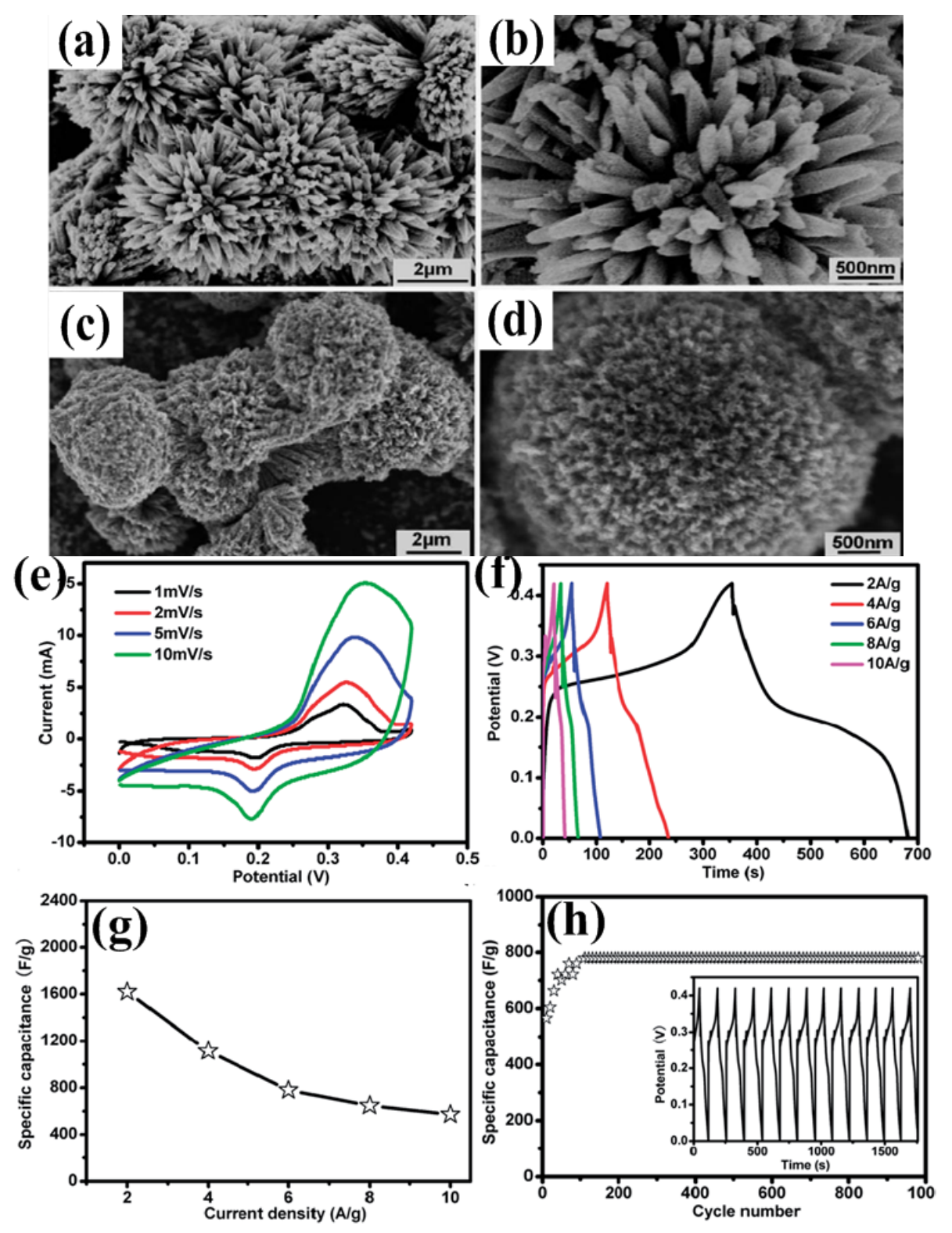

Figure 12. FESEM images of flower-like $\mathrm{NiCo}_{2} \mathrm{O}_{4}(\mathbf{a}$ and $\mathbf{b})$ and hierarchical mesoporous structured $\mathrm{NiCO}_{2} \mathrm{O}_{4}$ (c and d); electrochemical performance of hierarchical mesoporous $\mathrm{NiCo}_{2} \mathrm{O}_{4}$ electrodes. (e) $\mathrm{CV}$ curves at scan rates of $1.0,2.0,5.0$ and $10.0 \mathrm{mV} \cdot \mathrm{s}^{-1}$, respectively; (f) GCD curves at various current densities; (g) Effects of current density on its specific capacitance; (h) Cycling performance over 1000 cycles at a current density of $6.0 \mathrm{~A} \cdot \mathrm{g}^{-1}$. The inset shows the GCD curve at a current density of $6.0 \mathrm{~A} \cdot \mathrm{g}^{-1}[72]$.

In recent two years, the growth of $\mathrm{NiCo}_{2} \mathrm{O}_{4}$ on a conductive substrate attracts more and more attention. By this means, not only the conductivity of electrodes but also the specific surface areas is enhanced greatly. These unique composite electrodes may become ideal materials to improve the performance of pseudocapacitors. Several works have demonstrated the advantages of the composite electrodes. For example, mesoporous $\mathrm{NiCo}_{2} \mathrm{O}_{4}$ nanoneedles were grown on three-dimensional (3D) graphene-nickel foam and were then used to construct supercapacitor. The specific capacitance of $\mathrm{NiCo}_{2} \mathrm{O}_{4}$ nanoneedles was $1588 \mathrm{~F} \cdot \mathrm{g}^{-1}$ at $1 \mathrm{~A} \cdot \mathrm{g}^{-1}$ and the power density and energy density was $33.88 \mathrm{Wh} \cdot \mathrm{kg}^{-1}$ at $5 \mathrm{~kW} \cdot \mathrm{kg}^{-1}$, respectively [75]. Hierarchical porous $\mathrm{NiCo}_{2} \mathrm{O}_{4}$ films composed of 
nanowalls on nickel foam were synthesized via a facile hydrothermal method. A capacity of $130 \mathrm{~mA} \cdot \mathrm{h} \cdot \mathrm{g}^{-1}$ was achieved at $2 \mathrm{~A} \cdot \mathrm{g}^{-1}$ with $97 \%$ capacity maintained after 2000 cycles [76]. $\mathrm{NiCo}_{2} \mathrm{O}_{4}$ multiple hierarchical structures composed of 1D nanowires and 2D nanosheets were grown on Ni foam. $\mathrm{NiCo}_{2} \mathrm{O}_{4}$ exhibited a specific capacitance of even up to $2623.3 \mathrm{~F} \cdot \mathrm{g}^{-1}$, scaled to the active mass of $\mathrm{NiCo}_{2} \mathrm{O}_{4}$ sample at a current density of $1 \mathrm{~A} \cdot \mathrm{g}^{-1}$. A nearly constant rate performance of $68 \%$ was achieved at a current density ranging from 1 to $40 \mathrm{~A} \cdot \mathrm{g}^{-1}$, and the sample retained approximately $94 \%$ of its maximum capacitance even after 3000 continuous charge-discharge cycles at a consistently high current density of $10 \mathrm{~A} \cdot \mathrm{g}^{-1}$ [77]. The ultrathin $\mathrm{NiCo}_{2} \mathrm{O}_{4}$ nanosheets supported on nickel foam were prepared via a two-step process, electrodeposition method followed with thermal treatment. The as-prepared samples were directly fabricated as electrodes for supercapacitors, and the outstanding electrochemical performance of $2517 \mathrm{~F} \cdot \mathrm{g}^{-1}$ was achieved at $1 \mathrm{~A} \cdot \mathrm{g}^{-1}$ and could still maintain $1200 \mathrm{~F} \cdot \mathrm{g}^{-1}$ at current density of $15 \mathrm{~A} \cdot \mathrm{g}^{-1}$. The cyclic stability was also tested under current density of $8 \mathrm{~A} \cdot \mathrm{g}^{-1}$, and $64 \%$ of initial capacitance was still maintained after 800 cycles [78].

Although transition metal oxides, such as $\mathrm{RuO}_{2}, \mathrm{MnO}_{2}, \mathrm{NiO}$ and $\mathrm{Co}_{3} \mathrm{O}_{4}$, have been widely investigated for pseudo-capacitors, their practical applications are still limited due to their poor stability and low electrical conductivity [79]. While active carbon materials possess good conductivity and high stability. Thus, combining transition metal oxides with carbon materials may enhance the electric conductivity, and improve electrochemical performance of supercapacitors. Design and synthesis of transition metal oxides/active carbon materials were also reported [4,80-85]. For example, $\mathrm{RuO}_{2}$ /ordered mesoporous carbon materials were prepared by impregnating an ordered mesoporous carbon $\mathrm{CMK}-3$ with $\mathrm{RuCl}_{3} \cdot \mathrm{xH}_{2} \mathrm{O}$ solution followed by annealing in nitrogen atmosphere. The annealing temperature and the $\mathrm{RuO}_{2}$ content had great influence on the specific capacitance of composites. The highest specific capacitance reached $633 \mathrm{~F} \cdot \mathrm{g}^{-1}$ by adjusting synthetic conditions [4]. Metal oxide nanorods $\left(\mathrm{MnO}_{2}, \mathrm{SnO}_{2}, \mathrm{NiO}\right)$ inside mesoporous silica supported carbon nanomembranes (denoted as SS-CNM) were applied for electrodes to fabricate symmetrical supercapacitors. Owing to the high electrical conductivity of SS-CNM and the intimate contact between the carbon membrane and well-ordered metal oxide nanorods, specific capacitances of $\mathrm{MnO}_{2}$ nanorods/SS-CNM, $\mathrm{SnO}_{2}$ nanorods/SS-CNM, and $\mathrm{NiO}$ nanorods/SS-CNM were achieved to be 964,745 , and $620 \mathrm{~F} \cdot \mathrm{g}^{-1}$, respectively. In addition, less than $10 \%$ of capacitance decays over 10000 circles and energy density was $33.5,25.7$, and $21.6 \mathrm{Wh} \cdot \mathrm{kg}^{-1}$ for $\mathrm{MnO}_{2}$ nanorods/SS-CNM, $\mathrm{SnO}_{2}$ nanorods/SS-CNM, and NiO nanorods/SS-CNM, respectively (Figure 13) [79]. Mesoporous NiO/reduced graphene oxide composites were synthesized by a hydrothermal route. Because the $3 \mathrm{D}$ graphene conductive network and the mesoporous structure were favorable for charge transportation and electrolyte diffusion, $\mathrm{NiO} / \mathrm{RGO}$ composites exhibited high specific capacitance $\left(1016.6 \mathrm{~F} \cdot \mathrm{g}^{-1}\right)$ and good cycling stability (94.9\% capacitance retention after 5000 cycles) [85]. 

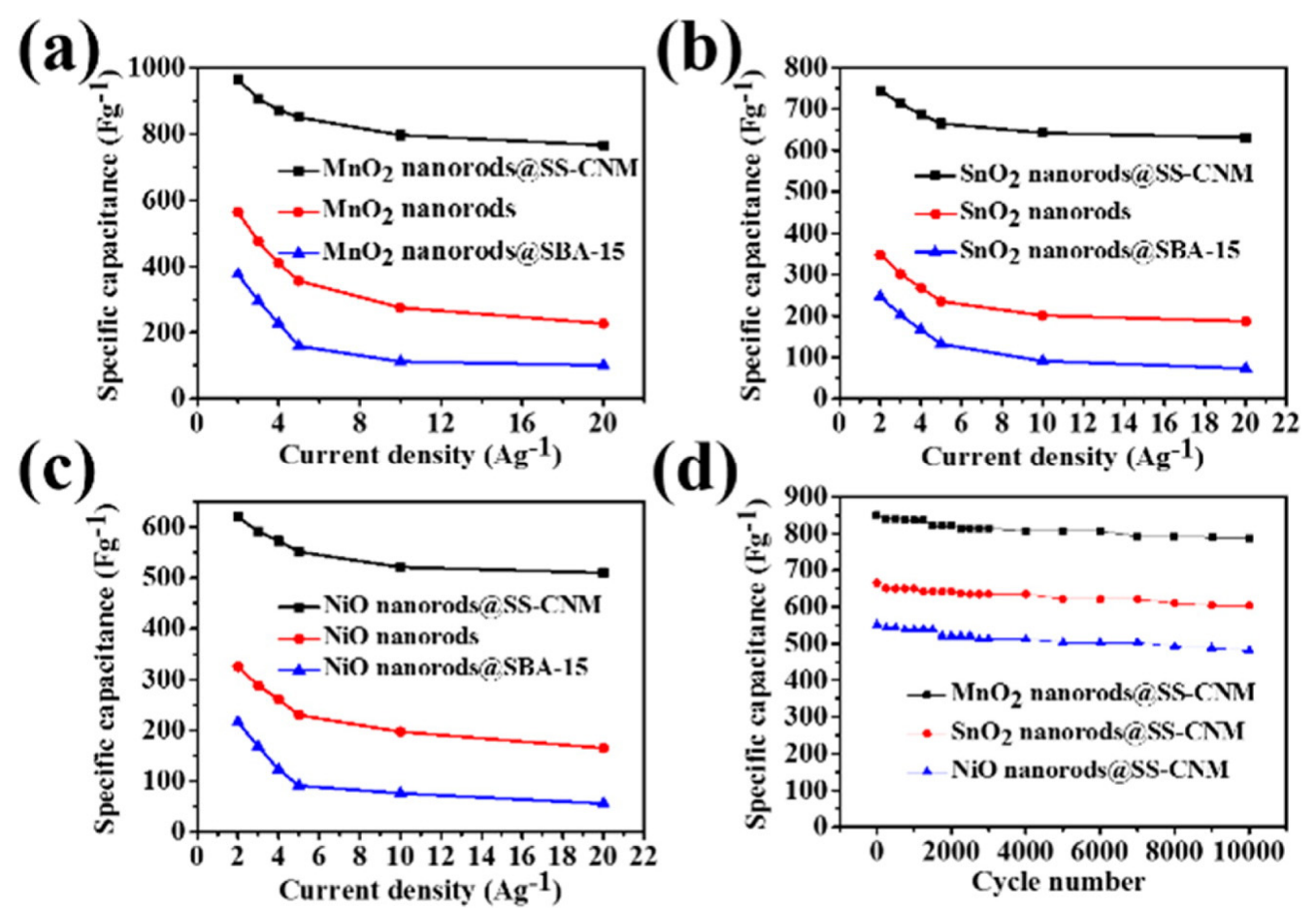

(d)

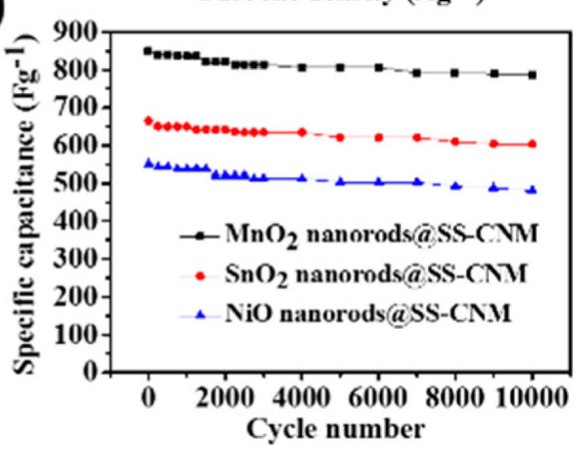

Figure 13. Curves of specific capacitance versus varied current density of $\mathrm{MnO}_{2}$ nanorods@SS-CNM (a); SnO 2 nanorods@SS-CNM (b); and NiO nanorods@SS-CNM (c); (d) Cycle life of $\mathrm{MnO}_{2}$ nanorods@SS-CNM, $\mathrm{SnO}_{2}$ nanorods@SS-CNM, and NiO nanorods@SS-CNM electrode materials at a scan rate of $0.1 \mathrm{~V} \cdot \mathrm{s}^{-1}[79]$.

\section{Conclusions}

Some recent achievements on mesoporous transition metal oxides $\left(\mathrm{RuO}_{2}, \mathrm{MnO}_{2}, \mathrm{NiO}, \mathrm{Co}_{3} \mathrm{O}_{4}\right.$ and $\mathrm{NiCo}_{2} \mathrm{O}_{4}$ ) for applications in supercapacitors were selected and reviewed. From this research, one can see that much progress has been made in the past decade. High specific capacity and excellent stability of nanomaterials have been observed from some mesoporous materials. In order to make the electrochemical performance of each material chosen in this mini-review more clear, their highest specific capacitance values and synthetic methods from literature mentioned in this paper are listed in Table 2. In the following research, simple synthetic methods that can produce metal oxide nanomaterials with appropriate morphology and are suitable for large-scale production should be a continuous concern for the purpose of real supercapacitor devices. In addition, attention should also focused on the design and synthesis of composite materials, such as transition metal oxides/metal, and transition metal oxides/active carbon, even on the combining of ionic liquids with mesoporous transition metal oxides. By doing so, the electrochemical performance of mesoporous transition metal oxide-based pseudo-capacitance could be envisioned to be improved substantially attributing to the synergistic effect of individual constituents. Especially, composite materials with 3D structures may provide more efficient and more rapid transportation for ions and electrons and thus result in higher electrochemical performance. 
Table 2. The best special capacitances of each material.

\begin{tabular}{ccc}
\hline Materials & Synthetic Method & Specific Capacitance $\left(\mathbf{F} \cdot \mathbf{g}^{-\mathbf{1}} \mathbf{)}\right.$ \\
\hline $\mathrm{RuO}_{2}$ & Sol-gel method & $720[18]$ \\
$\mathrm{MnO}_{2}$ & Template method & $297[39]$ \\
$\mathrm{NiO}$ & Gydrothermal method & $1700[46]$ \\
$\mathrm{Co}_{3} \mathrm{O}_{4}$ & $\begin{array}{c}\text { Sol-gel method followed } \\
\text { by freeze-drying }\end{array}$ & $742.3[60]$ \\
$\mathrm{Co}_{3} \mathrm{O}_{4} / \mathrm{Ni}$ & Robust adhesion \\
$\mathrm{NiCo}_{2} \mathrm{O}_{4}$ & Sydrothermal method assisted by & $2735-1471[64]$ \\
$\mathrm{NiCo}_{2} \mathrm{O}_{4} / \mathrm{Ni}$ & $\mathrm{PVP}$ and a post annealing treatment & $1619.1[72]$ \\
$\mathrm{RuO}_{2} /$ Order mesoporous carbon & Hydrothermal method & $2623.3[77]$ \\
$\mathrm{MnO}_{2} / \mathrm{Mesopous} \mathrm{silica} \mathrm{supported}_{\text {carbon nanomembranes }}$ & followed by annealing process & $633[4]$ \\
$\mathrm{NiO}_{\text {Mesopous silica supported }}$ & Soak followed by annealing & $964[79]$ \\
carbon nanomembranes & In situ grown & $620[79]$ \\
Co $\mathrm{O}_{4} / \mathrm{MWCNT}$ & In situ grown & $418[80]$ \\
\hline
\end{tabular}

\section{Acknowledgments}

This work was supported by the National Natural Science Foundation of China (Grant No. 51273076 and No. 51473061), and the State Key Laboratory of Laser Interaction with Matter (Grant No. SKLLIM1403).

\section{Author Contributions}

Y. Wang and Y.-W. Yang wrote the first draft of the manuscript. Editing and revisions were carried out collaboratively by all the authors.

\section{Conflicts of Interest}

The authors declare no conflict of interest.

\section{References}

1. Huang, L.; Chen, D.C.; Ding, Y.; Feng, S.; Wang, Z.L.; Liu, M.L. Nickel-cobalt hydroxide nanosheets coated on $\mathrm{NiCo}_{2} \mathrm{O}_{4}$ nanowires grown on carbon fiber paper for high-performance pseudocapacitors. Nano Lett. 2013, 13, 3135-3139.

2. Wang, H.W.; Yi, H.; Chen, X.; Wang, X.F. One-step strategy to three-dimensional graphene $/ \mathrm{VO}_{2}$ nanobelt composite hydrogels for high performance supercapacitors. J. Mater. Chem. A 2014, 2 , $1165-1173$.

3. Simon, P.; Gogotsi, Y. Materials for electrochemical capacitors, Nat. Mater. 2008, 7, 845-854. 
4. Li, H.F.; Wang, R.D.; Cao, R. Physical and electrochemical characterization of hydrous ruthenium oxide/ordered mesoporous carbon composites as supercapacitor. Microporous Mesoporous Mater. 2008, 111, 32-38.

5. Wu, M.Q.; Gao, J.H.; Zhang, S.R.; Chen, A. Synthesis and characterization of aerogel-like mesoporous nickel oxide for electrochemical supercapacitors. J. Porous Mater. 2006, 13, 407-412.

6. Wang, G.P.; Zhang, L.; Zhang, J.J. A review of electrode materials for electrochemical supercapacitors. Chem. Soc. Rev. 2012, 41, 797-828.

7. Salunkhe, R.R.; Lin, J.J.; Malgras, V.; Dou, S.X.; Kim, J.H.; Yamauchi, Y. Large-scale synthesis of coaxial carbon nanotube/ $\mathrm{Ni}(\mathrm{OH})_{2}$ composites for asymmetric supercapacitor application. Nano Energy 2015, 11, 211-218.

8. Tan, J.; Salunkhe, R.R.; Liu, J.; Torad, N.L.; Imura, M.; Furukawa, S.; Yamauchi, Y. Thermal conversion of core-shell metal-organic frameworks: A new method for selectively functionalized nanoporous hybrid carbon. J. Am. Chem. Soc. 2015, 137, 1572-1580.

9. Salunkhe, R.R.; Tang, J.; Kamachi, Y.; Nakato, T.; Kim, J.H.; Yamauchi, Y. Asymmetric supercapacitors using 3D nanoporous carbon and cobalt oxide electrodes synthesized from a single metal-organic framework. ACS Nano 2015, 9, 6288-6296.

10. Tarascon, J.M.; Armand, M. Issues and challenges facing rechargeable lithium batteries. Nature 2001, 414, 359-367.

11. Whittingham, M.S. Lithium batteries and cathode materials. Chem. Rev. 2004, 104, 4271-4301.

12. Brezesinski, T.; Wang, J.; Tolbert, S.H.; Dunn, B. Ordered mesoporous $\alpha-\mathrm{MoO}_{3}$ with iso-oriented nanocrystalline walls for thin-film pseudocapacitors. Nat. Mater. 2010, 9, 146-151.

13. Conway, B.E. Electrochemical Supercapacitors; Kluwer Academic: New York, NY, USA, 1999.

14. Winter, M.; Brodd, R.J. What are batteries, fuel cells, and supercapacitors? Chem. Rev. 2004, 104, 4245-4269.

15. Aricò, A.S.; Bruce, P.; Scrosati, B.; Tarasco, J.; Schalkwijk, W. Nanostructured materials for advanced energy conversion and storage devices. Nat. Mater. 2005, 4, 366-377.

16. Conway, B.E. Transition from supercapacitor to battery behavior in electrochemical energy storage. J. Electrochem. Soc. 1991, 138, 1539-1548.

17. Augustyn, V.; Simon, P.; Dunn, B. Pseudocapacitive oxide materials for high-rate electrochemical energy storage. Energy Environ. Sci. 2014, 7, 1597-1614.

18. Zheng, J.P.; Cygan, P.J.; Jow, T.R. Hydrous ruthenium oxide as an electrode material for electrochemical supercapacitors. J. Electrochem. Soc. 1995, 142, 2699-2703.

19. Sun, S.M.; Wang, P.Y.; Wu, Q.; Wang, S.; Fang, S.M. Template-free synthesis of mesoporous $\mathrm{MnO}_{2}$ under ultrasound irradiation for supercapacitor electrode. Mater. Lett. 2014, 137, 206-209.

20. Wang, Q.; Li, Z.S.; Huang, Y.G.; Li, Q.Y.; Wang, X.Y. A novel hybrid supercapacitor based on spherical activated carbon and spherical $\mathrm{MnO}_{2}$ in a non-aqueous electrolyte. J. Mater. Chem. 2010, 20, 3883-3889.

21. Yuan, C.Z.; Li, J.Y.; Hou, L.R.; Lin, J.D.; Pang, G.; Zhang, L.H.; Lian, L.; Zhang, X.G. Template-engaged synthesis of uniform mesoporous hollow $\mathrm{NiCo}_{2} \mathrm{O}_{4}$ sub-microspheres towards high-performance electrochemical capacitors. RSC Adv. 2013, 3, 18573-18578. 
22. Du, J.; Zhou, G.; Zhang, H.M.; Cheng, C.; Ma, J.M.; Wei, W.F.; Chen, L.B.; Wang, T.H. Ultrathin Porous $\mathrm{NiCo}_{2} \mathrm{O}_{4}$ Nanosheet Arrays on Flexible Carbon Fabric for High-Performance Supercapacitors. ACS Appl. Mater. Interfaces 2013, 5, 7405-7409.

23. Subramanian, V.; Hall, S.C.; Smith, P.H.; Rambabu, B. Mesoporous anhydrous $\mathrm{RuO}_{2}$ as a supercapacitor electrode material. Solid State Ionics 2004, 175, 511-515.

24. Bi, R.R.; Wu, X.L.; Cao, F.F.; Jiang, L.Y.; Guo, Y.G.; Wan, L.J. Highly dispersed $\mathrm{RuO}_{2}$ nanoparticles on carbon nanotubes: Facile synthesis and enhanced supercapacitance performance. J. Phys. Chem. C 2010, 114, 2448-2451.

25. Rakhi, R.B.; Chen, W.; Hedhili, M.N.; Cha, D.; Alshareef, H.N. Enhanced rate performance of mesoporous $\mathrm{Co}_{3} \mathrm{O}_{4}$ nanosheet supercapacitor electrodes by hydrous $\mathrm{RuO}_{2}$ nanoparticle decoration. ACS Appl. Mater. Interfaces 2014, 6, 4196-4206.

26. Rochefort, D.; Dabo, P.; Guay, D.; Sherwood, P.M.A. XPS investigations of thermally prepared $\mathrm{RuO}_{2}$ electrodes in reductive conditions. Electrochim. Acta 2003, 48, 4245-4252.

27. Galizzioli, D.; Tantardini, F.; Trasatti, S. Ruthenium dioxide: A new electrode material. 1. Behaviour in acid solutions of inert electrolytes. J. Appl. Electrochem. 1974, 4, 57-67.

28. Liu, T.C.; Pell, W.G.; Conway, B.E. Self-discharge and potential recovery phenomena at thermally and electrochemically prepared $\mathrm{RuO}_{2}$ supercapacitor electrodes, Electrochim. Acta 1997 , 42, 3541-3552.

29. Dubala, D.P.; Gund, G.S.; Holze, R.; Jadhav, H.S.; Lokhande, C.D.; Park, C.J. Solution-based binder-free synthetic approach of $\mathrm{RuO}_{2}$ thin films for all solid state supercapacitors. Electrochim. Acta 2013, 103, 103-109.

30. Liu, X.M.; Zhang, X.G. NiO-based composite electrode with $\mathrm{RuO}_{2}$ for electrochemical capacitors. Electrochim. Acta 2004, 49, 229-232.

31. Pusawale, S.N.; Deshmukh, P.R.; Gunjakar, J.L.; Lokhande, C.D. $\mathrm{SnO}_{2}-\mathrm{RuO}_{2}$ composite films by chemical deposition for supercapacitor application. Mater. Chem. Phys. 2013, 139, 416-422.

32. Li, X.; Gan, W.P.; Zheng, F.; Li, L.L.; Zhu, N.N.; Huang, X.Q. Preparation and electrochemical properties of $\mathrm{RuO}_{2} /$ polyaniline electrodes for supercapacitors. Synth. Met. 2012, 162, 953-957.

33. Wang, Y.G.; Zhang, X.G. Preparation and electrochemical capacitance of $\mathrm{RuO}_{2} / \mathrm{TiO}_{2}$ nanotubes composites. Electrochim. Acta 2004, 49, 1957-1962.

34. Liu, X.R.; Pickup, P.G. Ru oxide supercapacitors with high loadings and high power and energy densities. J. Power Sources 2008, 176, 410-416.

35. Song, Z.X.; Liu, W.; Zhao, M.; Zhang, Y.J.; Liu, G.C.; Yu, C.; Qiu, J.S. A facile template-free synthesis of $\alpha-\mathrm{MnO}_{2}$ nanorods for supercapacitor. J. Alloys Compd. 2013, 560, 151-155.

36. Yousefi, T.; Golikand, A.N.; Mashhadizadeh, M.H.; Aghazadeh, M. Template-free synthesis of $\mathrm{MnO}_{2}$ nanowires with secondary flower like structure: Characterization and supercapacitor behavior studies. Curr. Appl. Phys. 2012, 12, 193-198.

37. Nayak, P.K.; Munichandraiah, N. Mesoporous $\mathrm{MnO}_{2}$ synthesized by using a tri-block copolymer for electrochemical supercapacitor studies. Microporous Mesoporous Mater. 2011, 143, 206-214.

38. Zhou, Q.; Li, X.; Li, Y.G.; Tian, B.Z.; Zhao, D.Y.; Jiang, Z.Y. Synthesis and electrochemical properties of semicrystalline gyroidal mesoporous $\mathrm{MnO}_{2}$. Chin. J. Chem. 2006, 24, 835-839.

39. Devaraj, S.; Gabriel, G.S.; Gajjela, S.R.; Balaya, P. Mesoporous $\mathrm{MnO}_{2}$ and its capacitive behavior. Electrochem. Solid-State Lett. 2012, 15, A57-A59. 
40. Nayak, P.K.; Munichandraiah, N. Rapid sonochemical synthesis of mesoporous $\mathrm{MnO}_{2}$ for supercapacitor applications. Mater. Sci. Eng. B 2012, 177, 849-854.

41. Ming, B.S.; Li, J.L.; Kang, F.Y.; Pang, G.Y.; Zhang, Y.K.; Chen, L.; Xu, J.Y.; Wang, X.D. Microwave-hydrothermal synthesis of birnessite-type $\mathrm{MnO}_{2}$ nanospheres as supercapacitor electrode materials. J. Power Sources 2012, 198, 428-431.

42. Kim, B.K.; Chabot, V.; Yu, A.P. Carbon nanomaterials supported $\mathrm{Ni}(\mathrm{OH})_{2} / \mathrm{NiO}$ hybrid flower structure for supercapacitor. Electrochim. Acta 2013, 109, 370-380.

43. Yuan, C.Z.; Zhang, X.G.; Su, L.H.; Gao, B.; Shen, L.F. Facile synthesis and self-assembly of hierarchical porous $\mathrm{NiO}$ nano/micro spherical superstructures for high performance supercapacitors. J. Mater. Chem. 2009, 19, 5772-5777.

44. Lee, J.W.; Ahn, T.; Kim, J.H.; Ko, J.M.; Kim, J. Nanosheets based mesoporous NiO microspherical structures via facile and template-free method for high performance supercapacitors. Electrochim. Acta 2011, 56, 4849-4857.

45. Li, X.W.; Xiong, S.L.; Li, J.F.; Bai, J.; Qian, Y.T. Mesoporous NiO ultrathin nanowire networks topotactically transformed froma-Ni(OH $)_{2}$ hierarchical microspheres and their superior electrochemical capacitance properties and excellent capability for water treatment. J. Mater. Chem. 2012, 22, 14276-14283.

46. Yang, M.; Li, J.X.; Li, H.H.; Su, L.W.; Wei, J.P.; Zhou, Z. Mesoporous slit-structured NiO for high-performance pseudocapacitors. Phys. Chem. Chem. Phys. 2012, 14, 11048-11052.

47. Liu, F.; Yuan, W.; Li, T.Y.; Zhang, Z. Synthesis and electrochemical performance of mesoporous nickel oxide using mixed surfactant template. Mater. Res. Innov. 2015, 19, 70-75.

48. Wang, Y.L.; Chang, B.B.; Guan, D.X.; Pei, K.M.; Chen, Z.; Yang, M.; Dong, X.P. Preparation of nanospherical porous $\mathrm{NiO}$ by a hard template route and its supercapacitor application. Mater. Lett. 2014, 135, 172-175.

49. Meher, S.K.; Justin, P.; Rao, G.R. Microwave-mediated synthesis for improved morphology and pseudocapacitance performance of nickel oxide. ACS Appl. Mater. Interfaces 2011, 3, 2063-2073.

50. Kim, S.; Lee, J.; Ahn, H.; Song, H.; Jang, J. Facile route to an efficient NiO supercapacitor with a three-dimensional nanonetwork morphology. ACS Appl. Mater. Interfaces 2013, 5, 1596-1603.

51. Han, D.D.; Jing, X.Y.; Wang, J.; Yang, P.P.; Song, D.L.; Liu, J.Y. Porous lanthanum doped NiO microspheres for supercapacitor application. J. Electroanal. Chem. 2012, 682, 37-44.

52. Lu, Q.; Lattanzi, M.W.; Chen, Y.; Kou, X.; Li, W.; Fan, X.; Unruh, K.M.; Chen, J.G.; Xiao, J.Q. Supercapacitor electrodes with high-energy and power densities prepared from monolithic $\mathrm{NiO} / \mathrm{Ni}$ nanocomposites. Angew. Chem. Int. Ed. 2011, 50, 6847-6850.

53. Yuan, C.Z.; Yang, L.; Hou, L.R.; Shen, L.F.; Zhang, F.; Li, D.K.; Zhang, X.G. Large-scale $\mathrm{Co}_{3} \mathrm{O}_{4}$ nanoparticles growing on nickel sheets via a one-step strategy and their ultra-highly reversible redox reaction toward supercapacitors. J. Mater. Chem. 2011, 21, 18183-18185.

54. Lee, K.K.; Chin, W.S.; Sow, C.H. Cobalt-based compounds and composites as electrode materials for high-performance electrochemical capacitors. J. Mater. Chem. A 2014, 2, 17212-17248.

55. Xiao, Y.H.; Zhang, A.Q.; Liu, S.J.; Zhao, J.H.; Fang, S.M.; Jia, D.Z.; Li, F. Free-standing and porous hierarchical nanoarchitectures constructed with cobalt cobaltite nanowalls for supercapacitors with high specific capacitances. J. Power Sources 2012, 219, 140-146. 
56. Zhong, J.H.; Wang, A.L.; Li, G.R.; Wang, J.W.; Ou, Y.N.; Tong, Y.X. $\mathrm{Co}_{3} \mathrm{O}_{4} / \mathrm{Ni}(\mathrm{OH})_{2}$ composite mesoporous nanosheet networks as a promising electrode for supercapacitor applications. J. Mater. Chem. 2012, 22, 5656-5665.

57. Cao, L.; Lu, M.; Li, H.L. Preparation of mesoporous nanocrystalline $\mathrm{Co}_{3} \mathrm{O}_{4}$ and its applicability of porosity to the formation of electrochemical capacitance. J. Electrochem. Soc. 2005, 152, A871-A875.

58. Wang, L.; Liu, X.H.; Wang, X.; Yang, X.J.; Lu, L.D. Preparation and electrochemical properties of mesoporous $\mathrm{Co}_{3} \mathrm{O}_{4}$ crater-like microspheres as supercapacitor electrode materials. Curr. Appl. Phys. 2010, 10, 1422-1426.

59. Yuan, Y.F.; Xia, X.H.; Wu, J.B.; Huang, X.H.; Pei, Y.B.; Yang, J.L.; Guo, S.Y. Hierarchically porous $\mathrm{Co}_{3} \mathrm{O}_{4}$ film with mesoporous walls prepared via liquid crystalline template for supercapacitor application. Electrochem. Commun. 2011, 11, 1123-1126.

60. Wang, X.; Sumboja, A.; Khoo, E.; Yan, C.Y.; Lee, P. Cryogel synthesis of hierarchical interconnected macro-/mesoporous $\mathrm{Co}_{3} \mathrm{O}_{4}$ with superb electrochemical energy storage. J. Phys. Chem. C 2012, 116, 4930-4935.

61. Liu, X.M.; Long, Q.; Jiang, C.H.; Zhan, B.B.; Li, C.; Liu, S.J.; Zhao, Q.; Huang, W.; Dong, X.C. Facile and green synthesis of mesoporous $\mathrm{Co}_{3} \mathrm{O}_{4}$ nanocubes and their applications for supercapacitors. Nanoscale 2013, 5, 6525-6529.

62. Yan, D.L.; Zhang, H.; Chen, L.; Zhu, G.S.; Li, S.C.; Xu, H.R.; Yu, A.B. Biomorphic synthesis of mesoporous $\mathrm{Co}_{3} \mathrm{O}_{4}$ microtubules and their pseudocapacitive performance. ACS Appl. Mater. Interfaces 2014, 6, 15632-15637.

63. Xiong, S.L.; Yuan, C.Z.; Zhang, X.G.; Xi, B.J.; Qian, Y.T. Controllable synthesis of mesoporous $\mathrm{Co}_{3} \mathrm{O}_{4}$ nanostructures with tunable morphology for application in supercapacitors. Chem. Eur. J. 2009, 15, 5320-5326.

64. Yuan, C.Z.; Yang, L.; Hou, L.R.; Shen, L.F.; Zhang, X.G.; Lou, X.W. Growth of ultrathin mesoporous $\mathrm{Co}_{3} \mathrm{O}_{4}$ nanosheet arrays on $\mathrm{Ni}$ foam for high-performance electrochemical capacitors. Energy Environ. Sci. 2012, 5, 7883-7887.

65. Zhi, J.; Deng, S.; Zhang, Y.X.; Wang, Y.F.; Hu, A.G. Embedding $\mathrm{Co}_{3} \mathrm{O}_{4}$ nanoparticles in SBA-15 supported carbon nanomembrane for advanced supercapacitor materials. J. Mater. Chem. A 2013, 1, 3171-3176.

66. Padmanathan, N.; Selladurai, S.; Razeeb, K.M. Ultra-fast rate capability of a symmetric supercapacitor with a hierarchical $\mathrm{Co}_{3} \mathrm{O}_{4}$ nanowire/nanoflower hybrid structure in nonaqueous electrolyte. RSC $A d v$. 2015, 5, 12700-12709.

67. Xu, K.B.; Zou, R.J.; Li, W.Y.; Xue, Y.F.; Song, G.S.; Liu, Q.; Liu, X.J.; Hu, J.Q. Self-assembling hybrid $\mathrm{NiO} / \mathrm{Co}_{3} \mathrm{O}_{4}$ ultrathin and mesoporous nanosheets into flower-like architectures for pseudocapacitance. J. Mater. Chem. A 2013, 1, 9107-9113.

68. Wei, T.Y.; Chen, C.H.; Chien, H.C.; Lu, S.Y.; Hu, C.C. A cost-effective supercapacitor material of ultrahigh specific capacitances: Spinel nickel cobaltite aerogels from an epoxide-driven sol-gel process. Adv. Mater. 2010, 22, 347-351.

69. Wu, Z.B.; Zhu, Y.R.; Ji, X.B. NiCo2 $\mathrm{O}_{4}$-based materials for electrochemical supercapacitors. J. Mater. Chem. A 2014, 2, 14759-14772. 
70. Yuan, C.Z.; Li, J.Y.; Hou, L.R.; Yang, L.; Shen, L.F.; Zhang, X.G. Facile template-free synthesis of ultralayered mesoporous nickel cobaltite nanowires towards high-performance electrochemical capacitors. J. Mater. Chem. 2012, 22, 16084-16090.

71. Padmanathan, N.; Selladurai, S. Solvothermal synthesis of mesoporous $\mathrm{NiCo}_{2} \mathrm{O}_{4}$ spinel oxide nanostructure for high-performance electrochemical capacitor electrode. Ionics 2013, 19, 1535-1544.

72. Zhang, Y.F.; Ma, M.Z.; Yang, J.; Su, H.Q.; Huang, W.; Dong, X.C. Selective synthesis of hierarchical mesoporous spinel $\mathrm{NiCo}_{2} \mathrm{O}_{4}$ for high-performance supercapacitors. Nanoscale 2014, 6, 4303-4308.

73. Hsu, C.T.; Hu, C.C. Synthesis and characterization of mesoporous spinel $\mathrm{NiCo}_{2} \mathrm{O}_{4}$ using surfactant-assembled dispersion for asymmetric supercapacitors. J. Power Sources 2013, 242, 662-671.

74. Zhu, Y.R.; Wu, Z.B.; Jing, M.J.; Song, W.X.; Hou, H.S.; Yang, X.M.; Chen, Q.Y.; Ji, X.B. $3 \mathrm{D}$ network-like mesoporous $\mathrm{NiCo}_{2} \mathrm{O}_{4}$ nanostructures as advanced electrode material for supercapacitors. Electrochim. Acta 2014, 149, 144-151.

75. Yu, M.; Chen, J.P.; Liu, J.H.; Li, S.M.; Ma, Y.X.; Zhang, J.D.; An, J.W. Mesoporous $\mathrm{NiCo}_{2} \mathrm{O}_{4}$ nanoneedles grown on 3D graphene-nickel foam for supercapacitor and methanol electro-oxidation. Electrochim. Acta 2015, 151, 99-108.

76. Zheng, Q.Y.; Zhang, X.Y.; Shen, Y.M. Construction of hierarchical porous $\mathrm{NiCo}_{2} \mathrm{O}_{4}$ films composed of nanowalls as cathode materials for high-performance supercapacitor. Mater. Res. Bull. 2015, 64, 401-404.

77. Zhou, Q.W.; Xing, J.C.; Gao, Y.F.; Lv, X.J.; He, Y.M.; Guo, Z.H.; Li, Y.M. Ordered assembly of $\mathrm{NiCo}_{2} \mathrm{O}_{4}$ multiple hierarchical structures for high-performance pseudocapacitors. ACS Appl. Mater. Interfaces 2014, 6, 11394-11402.

78. Fu, H.Y.; Wang, Z.Y.; Li, Y.H.; Zhang, Y.F. Electrochemical deposition of mesoporous $\mathrm{NiCo}_{2} \mathrm{O}_{4}$ nanosheets on $\mathrm{Ni}$ foam as highperformance electrodes for supercapacitors. Mater. Res. Innov. 2015, 19, S255-S259.

79. Zhi, J.; Deng, S.; Wang, Y.F.; Hu, A.G. Highly ordered metal oxide nanorods inside mesoporous silica supported carbon nanomembranes: High performance electrode materials for symmetrical supercapacitor devices. J. Phys. Chem. C 2015, 119, 8530-8536.

80. Lang, J.W.; Yan, X.B.; Xue, Q.J. Facile preparation and electrochemical characterization of cobalt oxide/multi-walled carbon nanotube composites for supercapacitors. J. Power Sources 2011, 196, 7841-7846.

81. Dong, X.P.; Shen, W.H.; Gu, J.L.; Xiong, L.M.; Zhu, Y.F.; Li, H.; Shi, J.L. MnO2-embedded-inmesoporous-carbon-wall structure for use as electrochemical capacitors. J. Phys. Chem. B 2006, 110, 6015-6019.

82. Li, G.R.; Feng, Z.P.; Ou, Y.N.; Wu, D.C.; Fu, R.W.; Tong, Y.X. Mesoporous $\mathrm{MnO}_{2} / \mathrm{carbon}$ aerogel composites as promising electrode materials for high-performance supercapacitors. Langmuir 2010, 26, 2209-2213.

83. Liu, M.X.; Gan, L.H.; Xiong, W.; Xu, Z.J.; Zhu, D.Z.; Chen, L.W. Development of $\mathrm{MnO}_{2} /$ porous carbon microspheres with a partially graphitic structure for high performance supercapacitor electrodes. J. Mater. Chem. A 2014, 2, 2555-2562. 
84. Kiani, M.A.; Khani, H.; Mohammadi, N. $\mathrm{MnO}_{2} /$ ordered mesoporous carbon nanocomposite for electrochemical supercapacitor. J. Solid State Electrochem. 2014, 18, 1117-1125.

85. Cao, P.Q.; Wang, L.C.; Xu, Y.J.; Fu, Y.B.; Ma, X.H. Facile hydrothermal synthesis of mesoporous nickel oxide/reduced graphene oxide composites for high performance electrochemical supercapacitor. Electrochim. Acta 2015, 157, 359-368.

(C) 2015 by the authors; licensee MDPI, Basel, Switzerland. This article is an open access article distributed under the terms and conditions of the Creative Commons Attribution license (http://creativecommons.org/licenses/by/4.0/). 